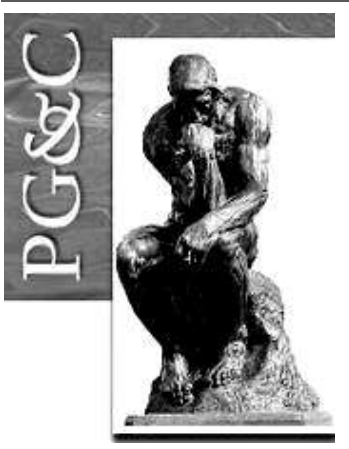

\title{
REDES DE RELACIONAMENTO: A ATUAÇÃO DOS STAKEHOLDERS NO MERCADO DE BENS SIMBÓLICOS DA EDUCAÇÃO
}

\author{
Roberto Bazanini \\ Doutor em Comunicação e Semiótica pela Pontifícia Universidade Católica \\ de São Paulo, Brasil. Professor da Universidade Paulista, Brasil. \\ E-mail: robertobazanini@gmail.com \\ Ivonaldo Vicente da Silva \\ Mestre em Administração de Empresas pela Universidade Paulista, Brasil. \\ E-mail: ivonaldosiva@gmail.com \\ Homero Leoni Bazanini \\ Doutorando em Comunicação Social pela Universidade Paulista, Brasil. \\ E-mail: $\underline{\text { homeroleba@uol.com.br }}$ \\ Marcos Antônio Biff \\ Mestre em Ciências Humanas pela Universidade Guarulhos, Brasil. \\ Professor da Universidade Municipal de São Caetano do Sul, Brasil. \\ E-mail: $\underline{\text { mbiffi@uscs.edu.br }}$

\section{Karina Rodrigues Negrão Mendes} \\ Graduanda em Administração de Empresas pela Universidade Paulista, \\ Brasil. \\ E-mail: Krmendes@bol.com.br
}

\begin{abstract}
Resumo
A pesquisa tem como objetivo investigar e analisar uma rede de relacionamento do mercado de bens simbólicos da educação tendo como objeto de pesquisa um grupo educacional situado na zona leste da cidade de São Paulo. Nesse mercado as redes de relacionamento se tornaram cada vez mais estratégicas para o alcance de vantagem competitiva diante da concorrência cada vez mais intensa. O problema da pesquisa surgiu a partir das experiências vividas pelos pesquisadores em decorrência das observações relativa às contribuições e influências que os stakeholders exercem em sua atuação nas redes de relacionamentos de uma organização de mercado de bens simbólicos da educação. A pesquisa do tipo descritiva, utilizou como instrumento de coleta de dados a entrevista semiestruturada amparada por formulários, acompanhada da técnica de observação não participante. Os resultados da pesquisa indicam que a forma como organização atua na sua rede de relacionamento pode ser crucial para a manutenção de suas atividades econômicas, pois as negociações com base nas questões éticas, de compromisso moral e criação de valor, podem ser diferenciais motivadores para que os stakeholders permaneçam atuando de forma colaborativa na rede. A contribuição da pesquisa está em discutir as vantagens, em termos estratégicos, de se adotar ações direcionadas para o bem coletivo fortalecidas por ações estratégicas que privilegiem os princípios de equidade e compromisso moral.
\end{abstract}

Palavras-chave: Mercado de Bens Simbólicos. Redes de Relacionamentos. Stakeholders

Perspectivas em Gestão \& Conhecimento, João Pessoa, v. 8, n. 1, p. 86-116, jan./abr. 2018. DOI: http://dx.doi.org/10.21714/2236-417X2018v8n1p86.

http://periodicos.ufpb.br/ojs2/index.php/pgc. ISSN: 2236-417X. Publicação sob Licença (cc) EY-NC-ND 


\title{
RELATIONSHIP NETWORKS: \\ STAKEHOLDERS ENGAGEMENT ACTIVITIES IN THE EDUCATION SYMBOLIC GOODS MARKET
}

\begin{abstract}
The research has as objective to investigate and analyze a relationship network of the symbolic goods market of education, having as object of research an educational group located in the eastern zone of the city of São Paulo. In this market relationship networks have become increasingly strategic to achieve competitive advantage in the face of increasingly intense competition. The research problem emerged from the experiences of researchers as a result of comments on contributions and influences that the stakeholders carry out in the relationship network of a symbolic goods market organization of education. The research of descriptive type used as data collection instrument, a semi-structured interview supported by forms as well a non-participating observation technique. The results of the research indicate that the way in which the organization operates in its relationship network can be crucial for the maintenance of its economic activities, since negotiations based on ethical, moral commitment and value creation can be the motivating factors for Stakeholders remain active in the network. The contribution of the research is to discuss the advantages in strategic terms of adopting actions directed toward the collective good, strengthened by the win-win policy, observing the principles of equity and moral commitment.
\end{abstract}

Keywords: Symbolic Goods Market. Relationship Networks. Stakeholders.

\section{INTRODUÇÃO}

A proposta do artigo está em investigar e analisar uma rede de relacionamento do mercado de bens simbólicos da educação tendo como objeto de pesquisa um grupo educacional situado na zona leste da cidade de São Paulo que cresceu acentuadamente nas últimas duas décadas. A análise terá como eixos teóricos: as características do mercado de bens simbólicos, a teoria dos stakeholders e as abordagens teóricas nas redes de relacionamentos.

Em relação à teoria dos stakeholders, comumente a análise desses três elementos permite perceber que os indivíduos ou grupo de indivíduos que não dispõem de poder, legitimidade ou urgência com relação aos demais agentes, provavelmente, não serão considerados públicos de interesse, o que facilita a priorização e direcionamento de um plano de comunicação com esses mesmos agentes.

O termo stakeholder possui significado abrangente. Envolve vários agentes: colaboradores, comunidade do entorno, clientes, acionistas, fornecedores, órgãos públicos, dentre outros. Decorrente da abrangência do termo surge a primeira questão no processo decisório da gestão empresarial: como realizar um diálogo efetivo com tantas partes envolvidas e diferentes interesses?

Em decorrência, as organizações devem avaliar e identificar quem realmente importa para o alcance dos seus objetivos estratégicos, por meio da realização de um mapeamento que permita identificar os públicos mais relevantes para a empresa, limitando assim, a complexidade proveniente do significado abrangente do termo.

Existem diferentes metodologias para a realização deste mapeamento para identificação dos stakeholders da organização. Para os propósitos da presente pesquisa foi adotada a proposta de Mitchell, Agle e Wood (1997), denominado Salience Model, proposta essa, que destaca os elementos poder, legitimidade e urgência como determinantes nas ações que se estabelecem entre os agentes.

Perspectivas em Gestão \& Conhecimento, João Pessoa, v. 8, n. 1, p. 86-116, jan./abr. 2018. 
Nesse ponto é preciso considerar que a identificação de stakeholders não é definitiva, razão pela qual, esse processo deve ser visto como uma construção, que pode sofrer mudanças com o passar do tempo, ou seja, a análise das partes interessadas deve considerar a situação do momento e os cenários futuros, visto que, talvez um grupo não priorizado em determinado momento, pode vir a possuir outros atributos no futuro, merecendo tratamento diferenciado.

Nessa perspectiva a análise dos elementos poder, legitimidade e urgência se apoia na classificação dos vários grupos que a organização deve privilegiar. Nas redes de relacionamentos é possível definir uma estratégia de abordagem, que garanta o uso eficiente de esforços para comunicar e gerenciar as expectativas das partes interessadas identificadas e classificadas, como forma de buscar recursos que lhes garantam resultados positivos e sustentáveis. Essas estratégias envolvem ações de cooperação e colaboração entre parceiros.

O modo como uma organização atua no mercado pode ser um diferencial que justifique seu crescimento. Para esse estudo de caso, foi escolhida uma organização do mercado de bens simbólicos da educação, com fins lucrativos, estabelecida na zona leste da cidade de São Paulo, tendo como diferencial a maneira como atua, pois, de acordo com sua política e modelo de relacionamento, busca se fortalecer no mercado, aumentar sua participação mediante o número de alunos matriculados e ainda expandir sua marca.

O objetivo da pesquisa está em investigar e analisar uma rede de relacionamento do mercado de bens simbólicos da educação tendo como objeto de pesquisa um grupo educacional situado na zona leste da cidade de São Paulo. Analisar a atuação estratégica dos stakeholders por intermédio de ações colaborativas, cooperativas e competitivas, como tipos de estratégias empregadas para o alcance de vantagem competitiva diante da concorrência cada vez mais intensa desse mercado.

Por intermédio de pesquisa descritiva, o problema da pesquisa surgiu a partir das experiências vividas pelos pesquisadores em decorrência das observações relativa às contribuições e influências que os stakeholders exercem em sua atuação nas redes de relacionamentos de uma organização de mercado de bens simbólicos da educação.

A contribuição da pesquisa está em discutir criticamente as vantagens em termos estratégicos de se adotar ações direcionadas para o bem coletivo fortalecidas pela política do ganha-ganha, observando-se os princípios de equidade e compromisso moral, implícitas nas abordagens da teoria do stakeholders.

Assim, o presente estudo foi estruturado em seis seções. Inicia com a introdução aqui apresentada e na sequência traz a fundamentação do trabalho alicerçado em três eixos teóricos: características do mercado de bens simbólicos, a teoria dos stakeholders com ênfase na vertente Salience Model e a abordagem social em redes. A terceira seção expõe e descreve os procedimentos metodológicos usados adotados na pesquisa, a quarta seção apresenta os resultados e as análises dos dados coletados, e em seguida, as considerações finais acompanhadas das limitações e sugestões para futuras pesquisas. Por fim, serão apresentadas as referências que contribuíram para o embasamento do presente estudo.

\section{FUNDAMENTAÇÃO TEÓRICA}

Com o intuito de se verificar os pressupostos teóricos que subsidiam a atuação dos stakeholders nas redes de relacionamentos serão apresentadas as concepções norteadoras que se referem ao mercado de bens simbólicos da educação. Parte-se do pressuposto que a pesquisa apoiada em três eixos teóricos: características do mercado de bens simbólicos, a teoria dos stakeholders e as abordagens teóricas nas redes de relacionamentos permite compreender o dinamismo desse mercado e a interatividade entre os diferentes stakeholders para o alcance de vantagem competitiva.

Perspectivas em Gestão \& Conhecimento, João Pessoa, v. 8, n. 1, p. 86-116, jan./abr. 2018. 
O crescimento do mercado de bens simbólicos se tornou realidade em todos os continentes em suas diferentes modalidades: turismo, desportos, religião, educação, etc. Mayer (2010) destaca o aspecto empreendedor e mercantil do futebol ao pesquisar o São Paulo Futebol Clube. Moreira, 2015, resultante da mercantilização do sagrado, analisa o surgimento indústria da música gospel, os shows-missa, a ritualidade triunfalista dos megatemplos, os megaeventos papais, o luxo de terreiros e locais de culto, a teatralidade ensaiada e, sobretudo, a produção "industrial" do próprio espetáculo religioso.

Na perspectiva do modelo de saliência dos stakeholders (MITCHEL, AGLE E WOOD, 1997), constatou-se que nas últimas décadas inúmeros trabalhos foram publicados sobre a atuação dos stakeholders no estudo de setores produtivos e também nas organizações ou instituições. Dentre essas pesquisas podem-se destacar os vários aspectos do emprego dessa abordagem nos mais diferentes setores organizacionais: Gonçalves et al (2008 analisa o setor hospitalar do Estado de São Paulo, Martins et al (2008) abordam o setor de transportes rodoviários de cargas no Brasil, Boaventura et al (2013) busca estabelecer conexões entre a percepção do gestor acerca da importância dos stakeholders e o nível de atendimento dos interesses desse mesmo stakeholder tendo como referencia a hierarquia obtida pela saliência em consonância com a dominância do agente. Bazanini et al (2016) discutem a viabilidade política e midiática do Templo de Salomão junto aos seus stakeholders no mercado de bens simbólicos da religião.

Em relação às teorias de redes, as publicações das últimas duas décadas, regra geral, posicionam-se criticamente em relação antiga concepção atomizada das organizações como unidades isoladas competindo entre si no mercado tornaram-se cada vez mais inadequada à dinâmica dos negócios contemporâneos (GULATI; NOHRIA; ZAHEER, 2000; HINGLEY, 2005; RICCOBONO; BRUCCOLERI; PERRONE, 2013). Ressaltam que as empresas estão imersas em redes de negócios alicerçadas em um conjunto de relacionamento que contém traços de competitividade que não existem em cada um dos negócios de forma isolada (ZACCARELLI et al., 2008).

Tendo como referência os atributos dos stakeholders envolvidos no empreendimento, nos estudos acima citados, a ênfase das análises se volta para o entendimento da coopetição, termo esse que constitui um neologismo ao combinar as palavras "competição" e "cooperação", introduzido originariamente na administração estratégica por Brandenburger e Nalebuff (1996).

\subsection{O mercado de bens simbólicos}

Bourdieu (2005) concebe que um bem simbólico se caracteriza quando um objeto artístico, cultural ou educacional recebe uma atribuição com base em valor mercantil, podendo ser consagrado pelas leis de mercado ao status de mercadoria. Nesse sentido, conforme o autor, o mercado de bens simbólicos é formado por produtos e serviços que refletem os signos e não sua utilidade material ou a ideia de custo-benefício.

De acordo com Bazanini (2005) quatro fatores que podem caracterizar o mercado de bens simbólicos, conforme Quadro 1:

Perspectivas em Gestão \& Conhecimento, João Pessoa, v. 8, n. 1, p. 86-116, jan./abr. 2018. 
Quadro 1 - Características do mercado de bens simbólicos

1. Todas as organizações de bens simbólicos estão em constante luta pela conquista da mente do consumidor;

2. O que uma organização ganha em adesão representa perdas para outros concorrentes;

3. Como o comportamento do consumidor desses bens tende à irracionalidade, é bastante comum o emprego de técnicas subliminares (qualquer estímulo que não é percebido de maneira consciente);

4. Em virtude da própria antropofagia do mercado, não raras vezes a opção de extinguir a concorrência é a única forma de sobrevivência

Fonte: Bazanini (2005, p. 179)

Historicamente Bourdieu (2005) foi um dos principais pensadores da era moderna a destacar que o mercado de bens culturais e simbólicos evoluiu desde a Idade Média se adaptando ao modelo de sociedade por meio de novas maneiras de se produzir cultura. 0 ponto crucial está na forma como esse tipo de mercado avançou a partir da Revolução Industrial (1760-1860), quando foram introduzidas novas técnicas para produção de mercadorias, inclusive os produtos ligados à cultura, o que possibilitou o surgimento da chamada indústria cultural.

Acentuadamente, a partir dos anos 90, o mercado de bens simbólicos expande-se nas atividades relacionadas ao turismo, aos desportos, à religião, a educação, etc.. No setor de turismo, Bazanini, et al (2015) avalia se na percepção dos dirigentes das empresas de turismo, a vantagem competitiva é alcançada quando a empresa se especializa nas necessidades e anseios de um segmento específico do mercado. Em relação aos desportos, Berton, Bazanini, Donaire (2013) analisam a estratégia empreendedora da gestão de Andrés Sanchez que possibilitou ao Sport Club Corinthians Paulista, em 2012, alcançar o primeiro lugar de empresa no futebol brasileiro e a sexta colocação no cenário mundial. No campo religioso, Bazanini, Miklos (2016) discutem criticamente a viabilidade política e midiática nas atuações dos stakeholders no Templo de Salomão. MARKOFF (2013) aborda as transformações no processo educacional, os desafios e as perspectivas futuras que estão presentes na economia globalizada.

Nessa linha de raciocínio que associa o processo educacional à economia globalizada, é possível observar que o sistema de ensino (educação) acaba por reproduzir comportamentos e valores que, de alguma maneira, estão relacionados não somente ao mercado de bens simbólicos, mas também ao conjunto da sociedade.

Assim, a educação constitui um elemento fundamental na formação do indivíduo, da família, da escola e das demais instituições formadoras de um capital cultural ou social. Assim, como a educação é um fator importante para o mercado de produção de bens culturais e simbólicos, Bourdieu e Passeron (2011) salientam:

Instrumento fundamental da continuidade histórica, a educação considerada como processo através do qual se opera no tempo a reprodução do arbitrário cultural, pela mediação da produção do hábito produtor de práticas de acordo com o arbitrário cultural, isto é, pela transmissão da formação como informação capaz de "informar" duravelmente os receptores (BOURDIEU; PASSERON, 2011, p. 54).

Bourdieu (2007) enfatiza ainda existir um poder simbólico utilizado como forma de condicionamento pelas classes dominantes que se tornam beneficiárias de um capital simbólico, disponibilizado e reproduzido pelas instituições que possibilita, de alguma forma, o exercício do poder: "[...] esse poder, o poder invisível, só pode ser exercido com a 
cumplicidade daqueles que não querem saber que lhe estão sujeitos ou mesmo que o exercem" (BOURDIEU, 2007, p. 7).

Desse modo, a competitividade no mercado de bens simbólicos possui especificidades decorrentes do tipo de ambientação que as estratégias necessariamente assumem e, consequentemente, a atuação dos stakeholders adquire características próprias.

\subsection{Teoria dos stakeholders}

O termo stakeholder, segundo Freeman (1984), foi mencionado pela primeira vez em um memorando do Stanford Research Institute - SRI em 1963 e indicava que uma organização não poderia sobreviver sem o apoio dessas partes interessadas. De acordo com Freeman (1984), o termo foi utilizado também por Igor Ansoff e Robert Stewart em trabalhos realizados no mesmo instituto. No decorrer do tempo, de acordo com Freeman (1984), na década de 1970, pesquisadores da linha da teoria dos sistemas, incluindo Russel Ackoff, também utilizaram o termo para salientar que muitos problemas na sociedade poderiam ser observados a partir da influência dos stakeholders no sistema.

Na década de 1980, o conceito de stakeholder começa a ganhar notoriedade, pois publicações ajudaram a divulgar esse conceito. Na década de 1990, percebe-se que o conceito de stakeholder avança no sentido de se tornar uma teoria mais completa, servindo de referencial teórico para diversas pesquisas. Frooman (1999) salienta que a Teoria dos Stakeholders tem seu marco histórico na obra de Freeman, Strategic Management: A Stakeholder Approach, publicada em 1984. Para Freeman (1984), são considerados stakeholders todos aqueles indivíduos, grupos ou empresas, que têm algum interesse ou relacionamento com uma organização. A empresa, por sua vez, com o objetivo de desenvolver estratégias, necessita obter respostas sobre quem são os seus stakeholders, o que eles querem e como eles tentarão atingir suas metas e satisfazer seus interesses.

Evan e Freeman (1988) advertem que os administradores devem assumir o dever de salvaguardar o bem-estar da entidade empresa. Para alcançar esse intuito, apesar do ambiente empresarial haver interesses concorrentes e eventualmente conflitantes, no qual, haverá certamente prejuízos para algumas das partes, sempre que possível, o gestor deve balancear as reivindicações dos múltiplos stakeholders, inclusive com o benefício de obterem as partes vantagens múltiplas numa relação ganha-ganha.

No intuito de observar o conjunto dos principais stakeholders envolvidos no ambiente de uma organização, Freeman (1984) propõe um modelo que simplificadamente demonstra como cada stakeholder está presente nesse ambiente, conforme Figura 1:

Perspectivas em Gestão \& Conhecimento, João Pessoa, v. 8, n. 1, p. 86-116, jan./abr. 2018. 
Figura 1 - Managing for stakeholders (gestão de stakeholders)

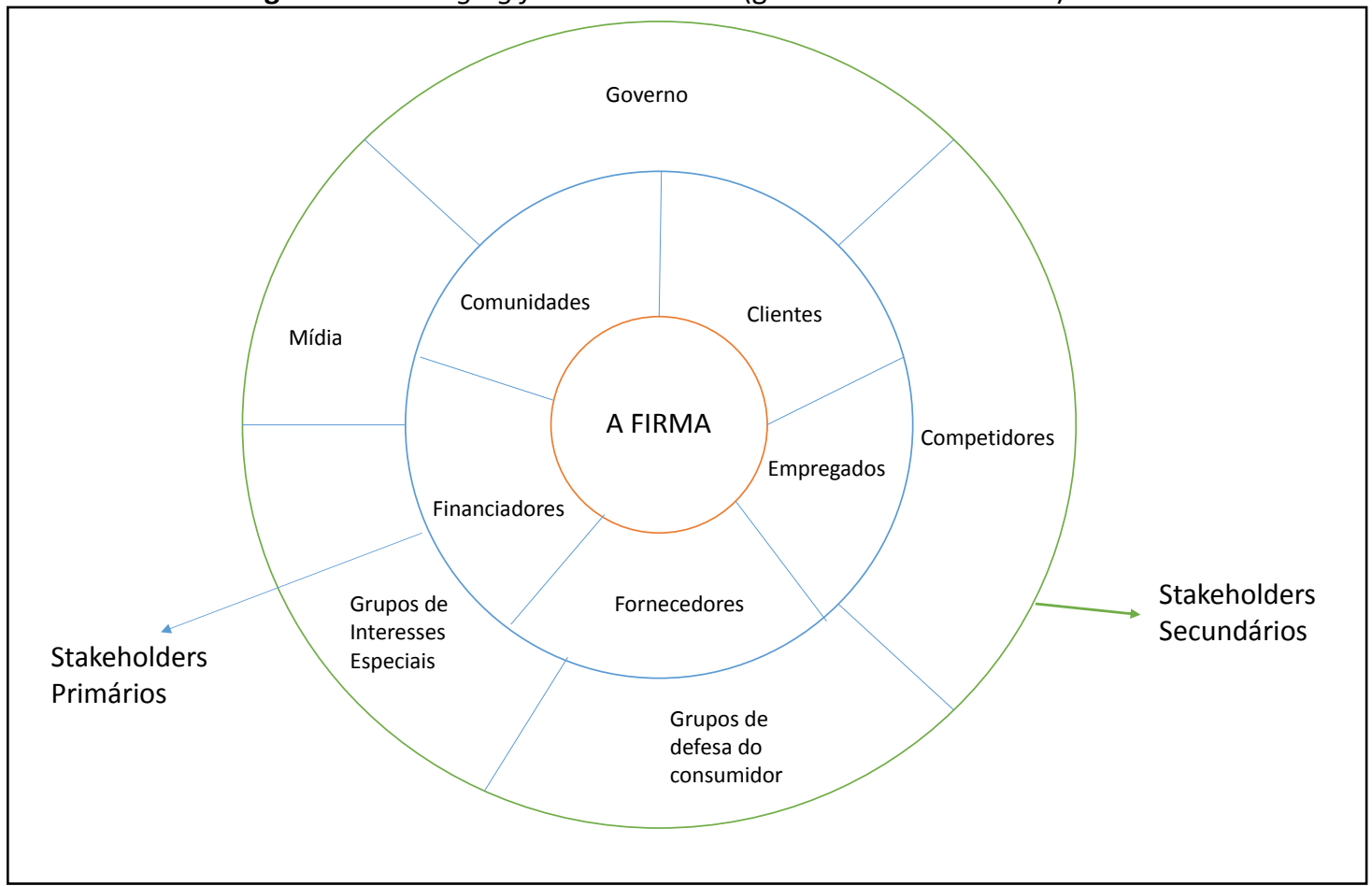

Fonte: Traduzido de Freeman $(1984 ; 2007)$

Segundo os estudos de Mitchell, Agle e Wood (1997), os stakeholders podem ser caracterizados em termos de poder, legitimidade e urgência. Quando os gestores percebem esses atributos de maneira acumulada nas pretensões de um stakeholder que deverá ser considerado o mais importante para a organização.

Para auxiliar no entendimento de como cada stakeholder pode influenciar ou contribuir com as atividades de uma organização, Mitchell, Agle e Wood (1997) definem algumas combinações entre os atributos de poder, legitimidade e urgência para que a organização possa criar estratégias de relacionamento, objetivando um equilíbrio nas ações envolvendo cada stakeholder. O Quadro 2 descreve uma síntese dessas combinações:

Quadro 2 - Classificação dos stakeholders com base Salience Model

\begin{tabular}{|c|c|}
\hline CLASSIFICAÇÃO & CARACTERÍSTICAS \\
\hline \multicolumn{2}{|l|}{ Stakeholders Latentes } \\
\hline \multirow[t]{3}{*}{ Saliência Baixa } & $\begin{array}{l}\text { Adormecidos: possuem um único atributo, o poder, mas por } \\
\text { não possuírem os outros, não o utilizam. } \\
\text { Ex.: Pessoas da organização com a capacidade de atração dos meios de } \\
\text { comunicação. }\end{array}$ \\
\hline & $\begin{array}{l}\text { Discricionário: possuem um único atributo, legitimidade, mas } \\
\text { não têm poder nem urgência em suas reivindicações. Ex.: Voluntários ou } \\
\text { associações sem fins lucrativos. }\end{array}$ \\
\hline & $\begin{array}{l}\text { Exigentes: possuem unicamente o atributo da urgência. Ex.: } \\
\text { Manifestantes por causas ecológicas. }\end{array}$ \\
\hline Stakeholders Expectantes & Dominantes: têm poder e legitimidade; as empresas devem buscar \\
\hline
\end{tabular}

Perspectivas em Gestão \& Conhecimento, João Pessoa, v. 8, n. 1, p. 86-116, jan./abr. 2018. 


\begin{tabular}{|l|l|}
\hline Saliência Moderada & $\begin{array}{l}\text { direcionar uma atenção especial aos interesses desses Stakeholders e } \\
\text { elaborar relatórios de prestação de contas para eles. Ex.: Comissões de } \\
\text { empregados. }\end{array}$ \\
$\begin{array}{l}\text { Dependentes: possuem legitimidade e urgência; são assim chamados, } \\
\text { pois dependem de outro Stakeholder, que tenha poder, para influenciar a } \\
\text { empresa para o atendimento de sua reivindicação. Ex.: Grupos } \\
\text { ambientalistas; empregados em condições de trabalho ilegais. }\end{array}$ \\
\hline Stakeholders Definitivos & $\begin{array}{l}\text { Perigosos: possuem urgência e poder; podem ser coercitivos e violentos. } \\
\text { Ex.: Preservação do meio ambiente. }\end{array}$ \\
\hline Saliência Alta & $\begin{array}{l}\text { Possuem os três atributos: poder, legitimidade e urgência. Segundo o o } \\
\text { modelo, os gestores possuem claramente o dever de atender e priorizar } \\
\text { os interesses desse tipo de Stakeholder. Ex.: Acionista. }\end{array}$ \\
\hline Não influencia nem recebe influência direta.
\end{tabular}

Fonte: Adaptado de Mitchell, Agle e Wood (1997)

Para um melhor entendimento em relação à integração dos atributos referentes à classificação dos stakeholders, disposto na Figura 2 pode-se observar como cada tipo de stakeholder está disposto segundo o grau de poder, legitimidade e urgência que possuem.

Figura 2 - Modelo de saliência dos stakeholders

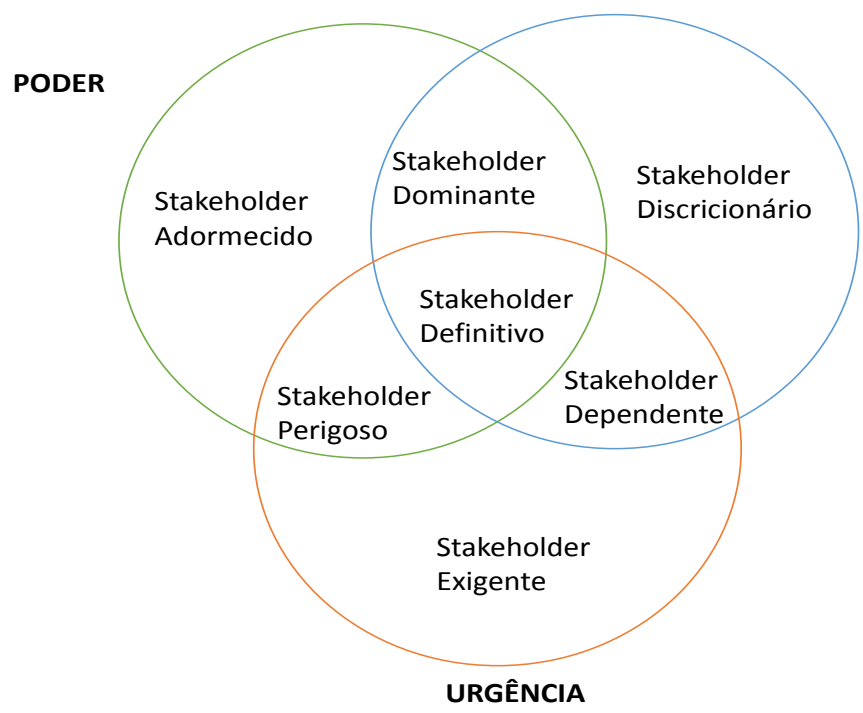

LEGITIMIDADE

Fonte: Mitchell, Angle e Wood (1987). Traduzido pelo Autor

Em consonância com essa disposição, Savageet al. (1991) adverte que os stakeholders podem colaborar com a organização ou ser uma ameaça para ela, e que muitas vezes, no relacionamento com os stakeholders, os seus interesses são ignorados e, com isso, o seu potencial de cooperação poderá ser negligenciado ou não considerado. Acrescenta ainda que a organização deve observar o grau de complexidade do relacionamento com múltiplos stakeholders com interesses e objetivos também variados. Os autores reforçam que a organização deve ter total entendimento do poder de ameaça e de cooperação de cada stakeholder, pois necessita se prevenir em relação às atitudes deles.

Perspectivas em Gestão \& Conhecimento, João Pessoa, v. 8, n. 1, p. 86-116, jan./abr. 2018. 
De acordo com Donaldson e Preston (1995), os administradores precisam reconhecer os diferentes grupos envolvidos com a empresa e quais são os seus reais interesses, e em conjunto com a análise de dados empíricos, verificar evidências acerca das relações entre a gestão de stakeholders e a realização dos objetivos corporativos, com ênfase nos aspectos normativo, descritivo e instrumental na abordagem de stakeholders.

O aspecto normativo prescreve como a gestão deve ser em consideração aos stakeholders; o aspecto descritivo traz uma descrição de como a gestão de stakeholders de fato acontece em um determinado contexto; e o aspecto instrumental discute a obtenção de recursos a partir do gerenciamento dos stakeholders (DONALDSON; PRESTON, 1995). Advertem que a organização que atende aos interesses de um amplo grupo de stakeholders desfruta de níveis mais elevados de desempenho do que aquelas que procuram atender a um ou alguns stakeholders (DONALDSON; PRESTON, 1995).

Nesse particular, as assertivas extraídas das pesquisas de Donaldson e Preston (1995) corroboram com a visão de Freeman (1984), consideram que o objetivo das organizações é atender aos interesses de todos os stakeholders, já que a organização depende deles para se manter em atividade. Para os autores, os stakeholders devem ser observados em um contexto mais amplo e não apenas como um simples meio para que os acionistas (shareholders) alcancem seus objetivos estratégicos.

Como mencionado anteriormente, na visão de Freeman (1984) proposta na década anterior ao pensamento de Donald e Preston (1995), a importância de a organização estaria em entender à parcela que cabe a cada stakeholder na geração e na apropriação de valor, pois com isso, a empresa pode se posicionar no que se refere às necessidades do seu ambiente. Ao exercer o poder de influenciar as organizações, as ações dos stakeholders podem ser, segundo Freeman (1984), conjunta e dominada, dividida ou passiva tendo em vista a distribuição do poder entre os vários stakeholders.

Para Mintzberg (2006), existe a manifestação do poder nos processos de barganha, confrontos e persuasão, quando se determina a estratégia de uma empresa, inclusive ao se observar a questão dos relacionamentos com outros stakeholders.

Segundo Clarkson (1995), os stakeholders podem ser classificados como primários e secundários. Os primários são todos aqueles que sem os quais a organização não consegue sobreviver, e os secundários todos aqueles que influenciam ou são influenciados pela organização, mas que não estão diretamente envolvidos em transações realizadas com essa organização, nem são essenciais para sua sobrevivência. Clarkson (1995) ainda salienta que, independentemente da classificação de um stakeholder, a organização deve desenvolver relacionamentos duradouros e de longo prazo com todos eles.

Jones (1995) também corrobora com Clarkson (1995) no sentido de reafirmar a necessidade da manutenção de um relacionamento duradouro com os stakeholders e salienta que um padrão de relacionamento baseado na confiança faz com que organização possa desenvolver vantagem competitiva sobre as demais.

$\mathrm{Na}$ linha de raciocínio desses autores, de maneira bem sintética, alguns princípios foram desenvolvidos pelo The Clarkson Centre for Business Ethics (1999) conforme Quadro 3: 
Quadro 3 - Princípios na gestão de stakeholders

\begin{tabular}{c|l|}
\hline Principio 1 & $\begin{array}{l}\text { Os gestores devem reconhecer e monitorar ativamente os interesses de todos os } \\
\text { stakeholders legitimos, e devem considerar adequadamente seus interesses na tomada de } \\
\text { decisão e nas operações. }\end{array}$ \\
\hline Principio 2 & $\begin{array}{l}\text { Os gestores devem ouvir e comunicar abertamente com os stakeholders sobre as suas } \\
\text { respectivas preocupações e contribuições, e sobre os riscos que assumem devido a seu } \\
\text { envolvimento com corporação. }\end{array}$ \\
\hline Principio 3 & $\begin{array}{l}\text { Os gestores devem adotar processos e modos de comportamento que são sensiveis às } \\
\text { preocupações e capacidades de cada stakeholder. }\end{array}$ \\
\hline Principio 4 & $\begin{array}{l}\text { Os gestores devem reconhecer a interdependência dos esforços e recompensas entre } \\
\text { stakeholders, e devem procurar realizar uma distribuição justa dos beneficios e ônus da } \\
\text { atividade corporativa entre eles, levando em conta seus respectivos riscos e } \\
\text { vulnerabilidades. }\end{array}$ \\
\hline Principio 5 & $\begin{array}{l}\text { Os gestores devem trabalhar em cooperação com outras entidades, pública e privada, } \\
\text { para garantir que os riscos e danos resultantes de atividades corporativas sejam } \\
\text { minimizados e, se não puderem ser evitados, sejam apropriadamente compensados. }\end{array}$ \\
\hline Principio 6 & $\begin{array}{l}\text { Os gestores devem evitar totalmente atividades que possam colocar em risco direitos } \\
\text { humanos inalienáveis (por exemplo, o direito á vida) ou dar origem a riscos, que sejam } \\
\text { claramente inaceitáveis para os stakeholders. }\end{array}$ \\
\hline Principio 7 & $\begin{array}{l}\text { Os gestores devem reconhecer os potenciais conflitos entre (a) seu próprio papel como } \\
\text { stakeholder da corporação, e (b) sua responsabilidade legal e moral para com os interesses } \\
\text { dos stakeholders, e devem abordar esses conflitos através da comunicação aberta, } \\
\text { informação adequada, sistemas de incentivos e, se necessário, de revisão de terceiros. }\end{array}$ \\
\hline
\end{tabular}

Fonte: The Clarkson Centre for Business Ethics (1999, p. 4)

No Quadro 3, os princípios propostos propiciam o reconhecimento de múltiplos e diversos interesses dos stakeholders que envolvem implícita e explicitamente conceitos de legitimidade.

Phillips (2003), avançando além desses princípios, propõe o conceito de legitimidade dos stakeholder, diferenciando a legitimidade normativa e derivativa. Considera os stakeholders com legitimidade normativa aqueles para os quais a organização tem um dever moral. Os stakeholders com legitimidade derivativa são aqueles com capacidade de exercer influência sobre a organização, incluindo os stakeholders com legitimidade normativa. Nessa definição são classificados como stakeholders possuidores de legitimidade normativa os empregados, acionistas, investidores, fornecedores, clientes e comunidade, enquanto concorrentes, mídia, meio-ambiente e grupos de interesse ou ativistas são stakeholders com legitimidade derivativa.

Todavia o termo legitimidade carece ainda de uma definição mais assertiva na perspectiva da teoria dos stakeholders (BARAKAT et al., 2016).

Assim, as tipologias e recomendações para se lidar com os diferentes stakeholders constituem os passos iniciais para se compreender a atuação desses mesmos agentes nas redes de relacionamento no mercado de bens simbólicos da educação.

\subsection{Redes de relacionamento}

O entendimento inicial para esse estudo está no fato de que toda organização deve estar inserida em uma rede de relacionamento, na qual não somente ela, mas todos os envolvidos considerados stakeholders trocam informações e efetuam transações (ROWLEY, 1997).

Alguns stakeholders envolvidos em uma rede de relacionamento e que têm pretensões em relação a uma organização podem, também, participar de outra rede de relacionamento

Perspectivas em Gestão \& Conhecimento, João Pessoa, v. 8, n. 1, p. 86-116, jan./abr. 2018. 
com outras pretensões em relação a outras organizações e assim sucessivamente (TICHY; TUSHMAN; FOMBRUN, 1979).

Os padrões de relacionamento considerados relativamente estáveis podem demonstrar como as organizações são constituídas, observando como cada relação é desenvolvida, qual é o papel de cada ator nesse relacionamento e quais são seus interesses individuais e coletivos (TICHY; TUSHMAN; FOMBRUN, 1979).

O que se deve observar, primeiramente, na análise de redes sociais é a interdependência dos atores e como suas posições nas redes podem influenciar as suas oportunidades, restrições e comportamentos (WASSERMAN; GALASKIEWICZ, 1994).

Granovetter (2007) aponta, em seus estudos, que as relações sociais podem ser responsáveis por conduzir à vida econômica das organizações e que a confiança entre as partes pode fortalecer esse relacionamento, com isso, a organização tende a evitar oportunismos. Destaca que melhor do que uma indicação de alguém com base na reputação é a experiência confiável daqueles que já trabalharam com esse indivíduo e obtiveram sucesso nas transações realizadas. Enfatiza ainda que o modelo de relacionamento pode ter um "enraizamento", denominado embeddedness, formalizado pelas extensas redes de relações sociais podendo ser pautadas na confiança e na predisposição mútua para solução de problemas, objetivando benefícios para os envolvidos (GRANOVETTER, 2007). O autor ainda acrescenta que as relações sociais podem ser um forte mecanismo para assegurar a confiança no grupo e, com isso, o oportunismo não será bem visto pelos envolvidos.

Se comparada a visão tradicional da Teoria dos Stakeholders com a abordagem em "Redes", pode-se perceber que, tanto uma quanto outra, observam os stakeholders, ou atores, como parte do ambiente da organização e como as relações podem afetar as atividades da organização (FREEMAN, 1984; ROWLEY, 1997).

A abordagem das influências pela visão tradicional está no limite da relação de cada stakeholder com a organização. Já na visão de "redes", as múltiplas interações vão a outros níveis de interações (ROWLEY, 1997), pois essas podem gerar padrões de influências que afetarão as atividades da organização em algum outro ponto e, por isso, devem ser monitoradas (NOHRIA; ECCLES, 1992).

Em algumas atividades, uma organização pode ser o centro de uma rede de relacionamento, envolvendo diversos stakeholders, cada um contribuindo com recursos e serviços no intuito de obter melhores resultados. Assim, as organizações podem ser consideradas "redes de relacionamento" com e entre stakeholders, necessitando do apoio desses para sobreviver (ROWLEY, 1997).

As ações de uma organização podem ser consideradas como respostas aos envolvidos (stakeholders) na rede de relacionamento, pois as influências podem ser identificadas por meio de múltiplas interações (ROWLEY, 1997).

Para Rowley (1997), o conjunto de stakeholders e de suas relações com uma organização podem ser entendidos como se fosse uma rede social na qual existem os stakeholders e suas relações singulares. Dessa forma, segundo o autor, os gestores de uma organização acabam por se inserirem em uma rede de stakeholders. Ainda de acordo com o exposto por Rowley (1997) e corroborando com Granovetter (2007), a força do relacionamento da organização depende exclusivamente da intensidade dos laços (forte ou fraco) com seus stakeholders.

Propõe que ao se observar uma rede de relacionamento o que se pode perceber é que uma organização nem sempre está no centro da rede, pois os laços de relacionamento são diversos, envolvendo muitas outras organizações, entidades, órgãos do governo, profissionais liberais ou clientes (ROWLEY, 1997). Particularmente, sobre a centralidade, propõe uma nova visão sobre a abordagem de Freeman (1984) que afirma que a organização está no centro das atenções, o que para a abordagem de redes não pode ser considerada uma verdade absoluta.

Perspectivas em Gestão \& Conhecimento, João Pessoa, v. 8, n. 1, p. 86-116, jan./abr. 2018. 
Salienta que nem sempre é a organização que está no centro de uma determinada rede, e que essa centralidade pode ser motivada por determinados interesses ou ações exclusivas de cada stakeholder envolvido. Ainda assim, o autor salienta que centralidade se refere ao poder obtido por meio da estrutura da rede, em oposição ao poder adquirido através dos atributos individuais.

Nessa linha de raciocínio, Rowley (1997) e Freeman (1984) propõem que os interesses em uma rede de relacionamento são mútuos e os resultados dessas relações acabam por gerar valores que são perceptíveis por todos os envolvidos, daí o interesse estar "conectado" a rede. Se o laço será fraco, ou forte, dependerá muito da forma de atuação desse stakeholder em relação à rede como um todo (ROWLEY,1997; GRANOVETTER, 2007).

Acresce-se, ainda, que uma rede de relacionamento precisa ser analisada sob dois quesitos primordiais: densidade e centralidade. De acordo com o autor, a densidade reflete o número de laços que os envolvidos possuem na rede e para uma rede ser considerada completa todos os stakeholders devem estar conectados uns aos outros o que, de certa forma, contraria a abordagem inicial de Freeman (1984).

Com base nessas reflexões, adverte que a organização deve observar como atua em sua rede de relacionamento, fortalecendo seus laços e procurando entender como essa rede se comporta em relação aos níveis de densidade e de centralidade.

Conclui que na perspectiva de redes, uma organização nem sempre está no centro das atenções, pois ela participa de uma rede de relacionamentos com diversos stakeholders e seus diversos interesses, ao ressaltar que salienta esse entendimento é crucial para que a organização possa desenvolver sua estratégia e propõe algumas com 'ções de interações na rede que poderão influenciar no modo como a organização interage com seus stakeholders.

Outro aspecto relevante diz respeito ao fato de uma organização, por meio de suas atividades econômicas, pode se tornar um objeto de interesses em que cada indivíduo ou empresa envolvida, direta ou indiretamente, buscam obter maior espaço para atuarem conjuntamente, no intuito de obter diferentes ganhos, inclusive os financeiros (FREEMAN, 1984; DONALDSON; PRESTON, 1995).

Post, Preston e Sachs (2002) apontam que as organizações são redes de relacionamentos que envolvem seus stakeholders, e que, com a atuação conjunta, buscam apoio para sobreviver no mercado, beneficiando esses stakeholders de forma coletiva por meio de gestão eficiente dessas redes.

Nessa perspectiva, o exposto por Post, Preston e Sachs (2002) em concordância com Rowley (1997), segundo o qual, as ações de uma organização derivam das influências do conjunto dos stakeholders que, de alguma maneira, influenciam essa organização por meio de múltiplas interações, como propõe Azevedo (2010), corroborando com a proposta de Rowley (1997):

\footnotetext{
Uma rede pode ser caracterizada pela combinação de expectativas, pela facilidade de troca de informações entre stakeholders e pelo potencial de formação de coalizões, que podem resultar na forte unificação de pretensões de vários stakeholders, pressionando uma organização para o atendimento de tais pretensões (AZEVEDO, 2010, p. 58).
}

Portanto, em consonância com o exposto por Azevedo (2010) e Rowley (1997), a proposta de observar a Teoria dos Stakeholders pela perspectiva de "redes" pode se justificar no sentido de que as atividades de uma organização, consequentemente, são oriundas de diversas outras atividades operacionalizadas por outros tantos stakeholders internos ou externos à organização.

Perspectivas em Gestão \& Conhecimento, João Pessoa, v. 8, n. 1, p. 86-116, jan./abr. 2018. 
Alguns autores convergem para o fato de que um relacionamento duradouro não pode ser pautado apenas em interesses econômicos, pois devem existir evidências de comprometimento, cooperação ou ainda confiança (TICHY; TUSHMAN; FOMBRUN, 1979; FREEMAN, 1984; ROWELY, 1997; GRANOVETTER, 2007).

Dessa forma, a análise das redes de relacionamentos no mercado de bens simbólicos da educação se torna de fundamental para o entendimento de como as contribuições e influências dos stakeholders são concebidas pela organização e, como essas interações podem ser analisadas pela gestão.

\section{METODOLOGIA}

\subsection{Tipo de Pesquisa}

A presente pesquisa, do tipo descritiva, realizada entre agosto e novembro de 2016, utilizou como instrumento de coleta de dados a entrevista semiestruturada amparada por formulário acompanhada da técnica de observação não participante.

Gil (2008) afirma que as pesquisas descritivas têm como objetivo relatar as características de uma determinada população ou fenômeno, ou ainda, o estabelecimento de relações entre variáveis. Já para Vergara (2000), a pesquisa descritiva expõe as características de determinada população ou fenômeno, estabelece correlações entre variáveis e define sua natureza. Salienta que inúmeros estudos são classificados como pesquisa descritiva e que, uma das características mais significativas desse método está na utilização de técnicas padronizadas para a coleta de dados.

Uma pesquisa para ser abrangente deve abordar os conceitos teóricos e práticos que envolvem o objeto de estudo, isso quando o assunto permite profundidade. Uma visão genérica dos fatos pode comprometer os resultados levando a uma conclusão não verdadeira em sua totalidade (YIN, 2010).

Em relação a abordagem qualitativa Godoy, (1995) apresenta suas principais características como complemento da pesquisa descritiva.

Considera o ambiente como fonte direta dos dados e o pesquisador como instrumento chave; possui caráter descritivo; o processo é o foco principal de abordagem e não o resultado ou o produto; a análise dos dados foi realizada de forma intuitiva e indutivamente pelo pesquisador; não requereu o uso de técnicas e métodos estatísticos; e, por fim, tem como preocupação maior a interpretação de fenômenos e a atribuição de resultados (GODOY, 1995, p.58).

No mesmo sentido, Gil (2008) acrescenta que o uso dessa abordagem pode garantir um aprofundamento na investigação das questões propostas para o entendimento do fenômeno em estudo e das suas relações. Segundo Malhotra (2001), esse modelo de pesquisa proporciona uma melhor compreensão do contexto da situação-problema.

Para Vergara (2000), o pesquisador deve definir o tipo de pesquisa com base no objetivo final da investigação. Para ele, a pesquisa pode ser exploratória, descritiva, explicativa, metodológica, aplicada ou ainda intervencionista e que ainda pode ser classificada como pesquisa de campo, de laboratório, documental, bibliográfica, experimental, participante, pesquisa-ação e, por fim, estudo de caso.

Segundo Eisenhardt (1989), o estudo de caso procura observar o entendimento das dinâmicas presentes dentro de uma única configuração. Os estudos de caso podem ser classificados como únicos ou múltiplos e podem combinar vários métodos para a coleta de

Perspectivas em Gestão \& Conhecimento, João Pessoa, v. 8, n. 1, p. 86-116, jan./abr. 2018. 
dados, exemplo disso são as entrevistas, os questionários e as observações (EISENHARDT, 1989; YIN, 2010).

Em consonância com essa ideia, Yin (2010) propõe que não existe uma fórmula específica para a escolha ou a construção das estratégias de estudo de caso o que, na realidade, depende da questão de pesquisa que norteia o estudo. Ainda para Yin (2010), quanto mais a questão de pesquisa procurar explicação para alguma circunstância presente, mais o método de estudo de caso se torna relevante. Inclusive para o autor, a estratégia de estudo de caso se torna relevante, também, quando existe a necessidade de uma descrição mais profunda e ampla sobre algum fenômeno social.

Particularmente, o estudo de caso, para Yin (2010, p.23), parte de uma investigação empírica que tem por objetivo abordar um fenômeno contemporâneo em profundidade em seu contexto de vida real, especialmente quando os limites entre o fenômeno e o contexto não são claramente evidentes. $O$ autor ainda acrescenta que o método se torna importante pois atende as seguintes razões (YIN, 2010, p. 23):

1. Para explicar ligações causais nas intervenções na vida real que são muito complexas para serem abordadas pelos surveys ou pelas estratégias experimentais;

2. Para descrever o contexto da vida real no qual a intervenção ocorreu;

3. Para fazer uma avaliação, ainda que de forma descritiva, da intervenção realizada; e

4. Para explorar aquelas situações nas quais as intervenções avaliadas não possuam resultados claros e específicos.

O presente estudo foi desenvolvido com base na estratégia de Estudo de Caso Único apresentada por Yin (2010), utilizando-se a pesquisa descritiva definida por Gil (2008), com abordagem qualitativa apresentada por Godoy (1995) e Malhotra (2001).

A escolha desse método se deve ao fato de que, como método de pesquisa, o estudo de caso pode ser utilizado, em muitas situações, para contribuir com o conhecimento dos fenômenos individuais, grupais, organizacionais, sociais, políticos e relacionados.

\subsection{Coleta de dados}

Em relação à pertinência do instrumento de coleta de dados, Gil (2008) concebe que existe três tipos de entrevistas que podem ser utilizadas: as estruturadas (uso de questionários aplicados verbalmente), as não estruturadas (realizadas com pouca ou nenhuma organização) e as semiestruturadas (contém questões-chave para guiar o entrevistador, mas também permite o debate sobre pontos e ideias).

Para Yin (2010), a entrevista é uma das fontes mais importantes de informação para o estudo de caso e não existe um ponto certo para o término da coleta de dados. O pesquisador, porém, deve verificar dois pontos cruciais: primeiro, a quantidade de fontes disponíveis; e segundo a coleta de dados deve ser mantida até que se tenha evidência confirmatória para a maioria dos tópicos principais.

Como mencionado anteriormente, as entrevistas foram complementadas pela técnica da observação não-participante, técnica essa, que acontece quando o pesquisador se mantém na posição de observador e expectador sem se envolver com o objeto da observação. Ou seja, não há interação social entre pesquisador e os sujeitos da pesquisa, os quais não sabem que estão sendo observados; a observação é usada, geralmente, como complemento de outras técnicas de coleta de dados (MINAYO, 2001).

Desse modo, a complementariedade entre essas técnicas empregadas como instrumento de coleta de dados teve como intuito aventar também a possibilidade de identificar os sinais de confiança, comprometimento e cooperação nas redes de relacionamentos de atuação dos stakeholders no mercado de bens simbólicos da educação.

Perspectivas em Gestão \& Conhecimento, João Pessoa, v. 8, n. 1, p. 86-116, jan./abr. 2018. 


\subsubsection{Etapas da Coleta de Dados}

A coleta de dados foi realizada em três etapas subseqüentes. Na Etapa 1, foi utilizado um formulário denominado "Formulário de Identificação dos Stakeholders", no qual os funcionários da organização (campo de pesquisa) indicaram quem são as empresas, pessoas, órgãos governamentais etc., que diretamente ou indiretamente se relacionam com a organização. Esse relacionamento poderia ser no sentido de obter vantagem financeira ou não, ou ainda, fazer cumprir alguma lei, norma ou procedimento.

De posse do resultado oriundo da Etapa 1, realizou-se a Etapa 2. Essa etapa consistia em uma entrevista amparada por um formulário denominado "Formulário de Poder e Identificação de Influência", a que cada entrevistado respondeu, com base no relatório da Etapa 1, a seguinte pergunta: "Quais são os cinco stakeholders que, em sua opinião, possuem maior poder de contribuir ou influenciar a organização (campo de pesquisa), tanto positiva quanto negativamente?"

Ainda sobre a Etapa 2, as indicações obedeceram à regra de maior importância, ou seja, do primeiro ao quinto (10 ao 5ㅇ), onde o primeiro indicado tem um maior poder de influência em relação aos demais e o quinto o menor poder de influência em relação aos cinco citados. No instante em que cada entrevistado indicava sua opção de stakeholder com poder de influência, também já descrevia como cada um deles influencia a organização (campo de pesquisa).

Esse formulário denominado "Formulário de Poder e Identificação de Influência", foi adaptado do estudo realizado por Melo e Régis (2013).

Com o objetivo de facilitar a identificação e guardar sigilo na Etapa 3, cada stakeholder recebeu um código que o identificará no mapa de relacionamento. Dessa forma, cada stakeholder tem um código de identificação, válido para toda a pesquisa, enquanto seu nome é preservado. Na Etapa 3, foi realizada uma entrevista amparada por um roteiro com 10 perguntas abertas e um "Formulário Mapa de Relacionamento". Essa entrevista foi realizada com cada tipo de stakeholder mencionado na Etapa 1, inclusive cada stakeholder foi entrevistado com base em um roteiro desenvolvido segundo sua função ou participação na rede de relacionamento da organização (objeto de estudo).

A entrevista, na Etapa 3, permitiu aos candidatos expressar, individualmente, suas opiniões e percepções sobre as atividades de cada stakeholder na rede de relacionamento da organização (objeto de estudo), inclusive como os valores são percebidos e a relação de equidade e compromisso ético/moral.

Finalizando a Etapa 3, cada entrevistado indicou todos aqueles, descritos como resultado da Etapa 1, com quem mantém algum tipo de relacionamento profissional ou de interesse (benefícios). Para anotar essas informações, foi utilizado um formulário denominado "Formulário Mapa de Relacionamento". Com base nessas identificações de relacionamento, foi verificada a questão da densidade da rede e a possível centralidade dos stakeholders.

Para a construção dos mapas de relacionamento foi utilizado o software UCINET. Para complementar as informações em relação à rede de relacionamento, a técnica de observação não participante foi utilizada em todas as etapas, de modo que algumas informações foram coletadas para enfatizar e confirmar o relacionamento entre os stakeholders envolvidos nessa rede.

Após a coleta de dados, foram realizadas as devidas "tabulações", ou seja, agrupamento dos dados conforme cada formulário. Para os dois formulários: "Formulário de Identificação" e "Formulário de Poder e Identificação de Influência", foram realizados, além do agrupamento dos dados e, embora de forma rudimentar, uma certa mensuração para identificar elementos mais indicados em cada um deles, conforme cada tópico. 


\subsection{Análise de dados}

A análise de dados desse foi realizada pelo método proposto por Bardin (1977), denominado Análise de Conteúdo que, segundo a autora, é definido como conjunto de instrumento metodológico que vai se aperfeiçoando constantemente, aplicando-se a discursos variados e servindo para desvendar o que parece estar oculto no texto.

Bardin (1977) esclarece que a técnica da Análise de Conteúdo consiste na tomada em conjunto das técnicas de análise das comunicações.

Um conjunto de técnicas de análise das comunicações visando obter, por procedimentos, sistemáticos e objetivos de descrição do conteúdo das mensagens, indicadores (quantitativos ou não) que permitam a inferência de conhecimentos relativos às condições de produção/recepção (variáveis inferidas) destas mensagens (BARDIN, 1977, p. 42).

Para Minayo (2001, p. 74), a análise de conteúdo pode ser compreendida muito mais como um conjunto de técnicas e tem duas funções: verificação de hipóteses, de questões e da descoberta do que está por trás dos conteúdos manifestos. Já para Moraes (1999):

A análise de conteúdo constitui uma metodologia de pesquisa usada para descrever e interpretar o conteúdo de toda classe de documentos e textos. [...] Constitui-se em bem mais do que uma simples técnica de análise de dados, representando uma abordagem metodológica com características e possibilidades próprias. (MORAES, 1999, p. 2).

Para Minayo (2001), Bardin (1977) e Moraes (1999), a análise de conteúdo é uma técnica que pode contribuir no sentido de organizar fatos, fenômenos e ainda categorizar dados que futuramente poderão ser comparados com o propósito inicial do estudo a ser realizado.

Como segundo passo, foram agrupadas as respostas consideradas similares. A partir da transcrição de todas as respostas, foram construídas categorias com base nos dados apresentados para que, posteriormente, fossem analisadas com base nas teorias propostas para este estudo. Os resultados foram utilizados para fins de comparação com a teoria, no sentido de justificar se a questão de pesquisa e os objetivos foram atendidos, bem como se as proposições foram validadas empiricamente.

\subsection{Procedimentos empregados}

Na elaboração do texto científico ao se coletar dados deve-se atentar para que os resultados alcançados possam ser comparados com as teorias utilizadas para a validação do estudo. Nesse sentido, se faz necessário utilizar os pressupostos de cada teoria acompanhado da explicação dos procedimentos empregados.

- Para o uso do Modelo de Saliência de Mitchell, Agle e Wood (1997) foi necessário observar a questão do Poder, Legitimidade e Urgência;

- Para a análise envolvendo os estudos de Phillips (1997) foi necessário observar como cada stakeholder percebia a ética e a moral, bem como a equidade, envolvidas nas negociações;

- Com base nos estudos relacionados a Teoria dos Stakeholders de Freeman (1984) e observando a questão de como cada stakeholder percebe o "valor" como fruto do 
relacionamento com a organização ou com a rede de relacionamento, essa variável valor também foi verificada;

- Em relação à proposta de Rowley (1997), foi preciso associar a atuação do stakeholder com a questão da densidade e da centralidade da rede.

\subsubsection{Pertinência desses procedimentos}

A pertinência desses procedimentos encontra eco nas teorias de diversos autores relacionados ao campo de estudo das ações estratégicas presentes nas redes de negócios. Genericamente, a interação entre esses procedimentos remete ao estudo do elemento poder na forma coercitiva presente nos estudos de Krausz (1988), Zaheer, Gozubuyuk, e Milanov (2010), Di Maggio e Powell (1983), Castells (2000).

Krausz (1988) salienta que nos relacionamentos oriundos entre os membros de uma rede há trocas sociais, e com ela pode surgir a questão do poder. Para Zaheer, Gozubuyuk, e Milanov (2010) os mecanismos teóricos para a análise de redes são: acesso a recursos, confiança, poder, controle e sinalização. Como o poder constitui-se em um dos quatro mecanismos teóricos para a análise de redes de negócios entre empresas, não pode ficar de fora no momento das análises.

Para Di Maggio e Powell (1983), o poder é a solução em alguns processos e tem sua origem em fontes coercitivas, normativas e miméticas. Para as fontes coercitivas há a presença de comportamentos que se confrontam com as regras existentes, já para as normativas, as expectativas culturais pressionam de alguma maneira pela conformidade e, por fim, nas miméticas, as organizações decidem copiar outras organizações em processos e atividades de sucesso, devido a algumas incertezas.

Já para Castells (2000), o poder é a ação do ser humano para impor a sua vontade sobre outros, pelo uso potencial ou real de instrumentos simbólicos ou físicos de violência.

Todavia a fusão do elemento poder nas redes de negócios ocorre tanto na forma coercitiva quanto não coercitiva. Com base nas expectativas culturais e miméticas faz-se necessário incluir também o conceito de poder relacional, pois segundo Foucault (1982), esse poder é exercido normalmente em uma relação entre duas ou várias partes, reflete os desequilíbrios que podem estar presentes nessas relações e, ainda, essas relações podem ser encontradas em qualquer parte da estrutura da sociedade, desde as relações do dia a dia entre indivíduos até nas relações entre grupos, como esclarece Reed (2014).

\footnotetext{
Poder relacional refere-se ao grau em que a estrutura de relações ou vínculos entre atores (onde essas relações ou vínculos podem ser constituídos de diversas formas, e os atores podem ser tanto individuais como coletivos) determina a capacidade de certos atores de controlar ou limitar as ações dos demais, de concretizar suas vontades sobre e contra as vontades dos outros e, de maneira geral, de dirigir a vida social, frequentemente em seu favor. Poder, na medida em que é algo relacional deriva das posicionalidades em uma estrutura de relações sociais. Essas posicionalidades podem ser dinâmicas, e algumas formas de poder relacional envolvem mecanismos sociais (REED, 2014, p. 488).
}

$\mathrm{Na}$ interação entre poder e legitimidade estão presentes as formas coercitivas e relacionais que interagem a legitimidade de determinado stakeholder. Pfeffer e Salancik (1978) salientam que a legitimidade organizacional não é dada antecipadamente, antes, é consequência da interpretação das ações a partir de sua comparação com valores socialmente legítimos.

Perspectivas em Gestão \& Conhecimento, João Pessoa, v. 8, n. 1, p. 86-116, jan./abr. 2018. 
Por sua vez, o atributo urgência "[...] reflete a necessidade por atenção imediata às demandas ou interesses de um determinado Stakeholder nas dimensões de sensibilidade temporal e de criticalidade". (MITCHELL; AGLE; WOOD, 1997, p. 867). Visto que, o atributo urgência é o grau em que a relação ou a reivindicação do stakeholder necessita de uma atenção imediata, sendo por questão de prazo (atrasos) ou ainda por ordem de importância, ou seja, algo crucial em uma relação entre stakeholders.

Assim, em termos teóricos, os procedimentos empregados na pesquisa reforçam a importância do Salience Model como fator explicativo no tratamento destinado a cada stakeholder nas redes de relacionamentos organizacionais para o alcance de vantagem competitiva.

\subsection{Sociograma e o UCINET}

O UCINET é um software desenvolvido com objetivo de visualizar graficamente com uma rede é formada, quais são os nós e laços, identificar grau de centralidade e densidade da rede entre outros fatores. A proposta deste estudo está em identificar quem são os stakeholders envolvidos na rede de relacionamento de organizações do mercado de bens simbólicos da educação. Nesse sentido, a utilização do UCINET é fundamental para representar graficamente esse relacionamento. Para ilustração, a Figura 3 representa como ficaria o modelo inicial proposto por Freeman (1984) para entendimento de quem são os possíveis stakeholders da organização.

Figura 3 - Representação do modelo de Freeman (1984) pelo UCINET

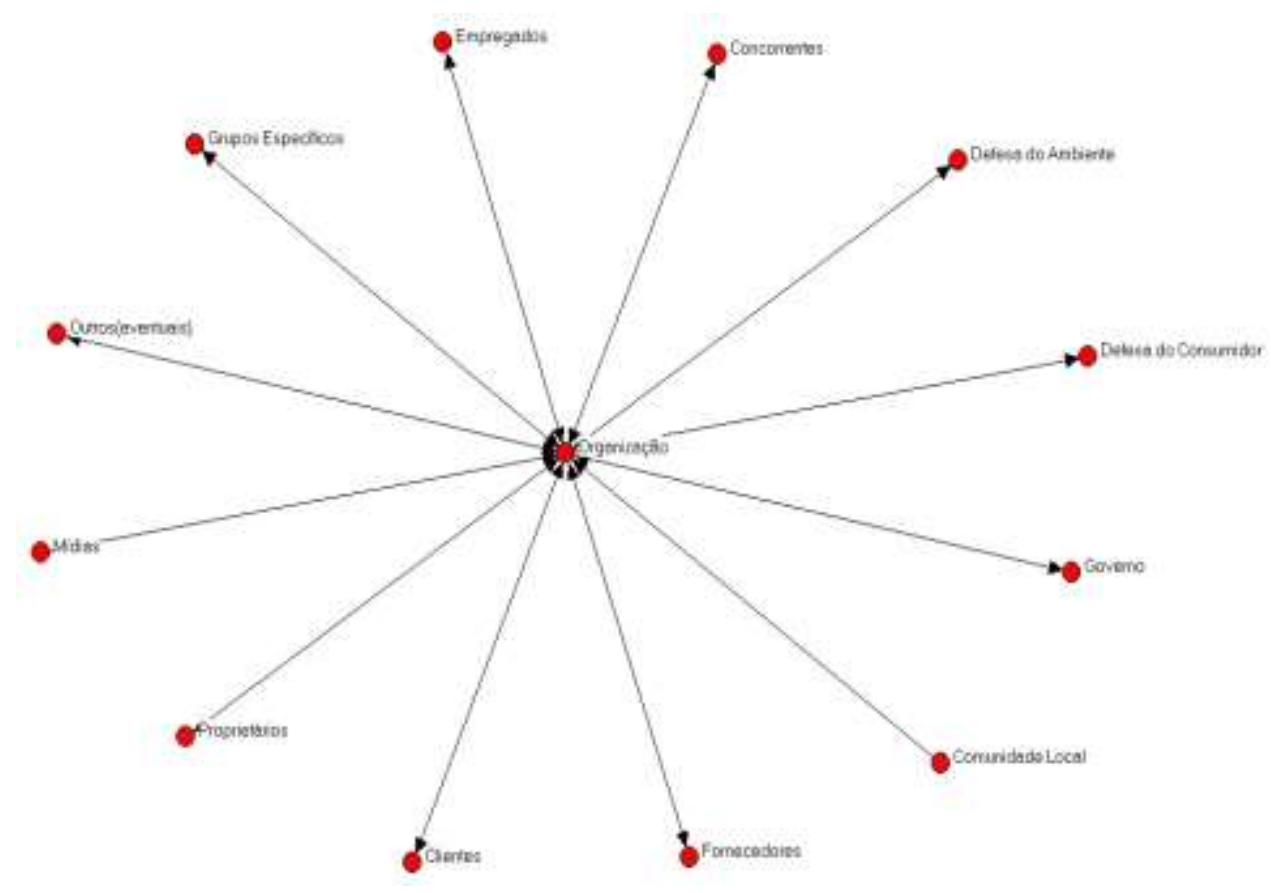

Fonte: Elaborado pelos autores (2016)

Pela proposta de Rowley (1997), a organização está em uma rede de stakeholders e esses mantêm um vínculo de relacionamento não só com a própria organização, mas com a

Perspectivas em Gestão \& Conhecimento, João Pessoa, v. 8, n. 1, p. 86-116, jan./abr. 2018. 
maioria dos envolvidos nessa rede. O modelo proposto por Freeman (1984) poderia ser adaptado para ter um formato que descrevesse os relacionamentos, um exemplo bem genérico está na Figura 4.

Figura 4 - Modelo de Freeman (1984) representado por uma rede de relacionamentos

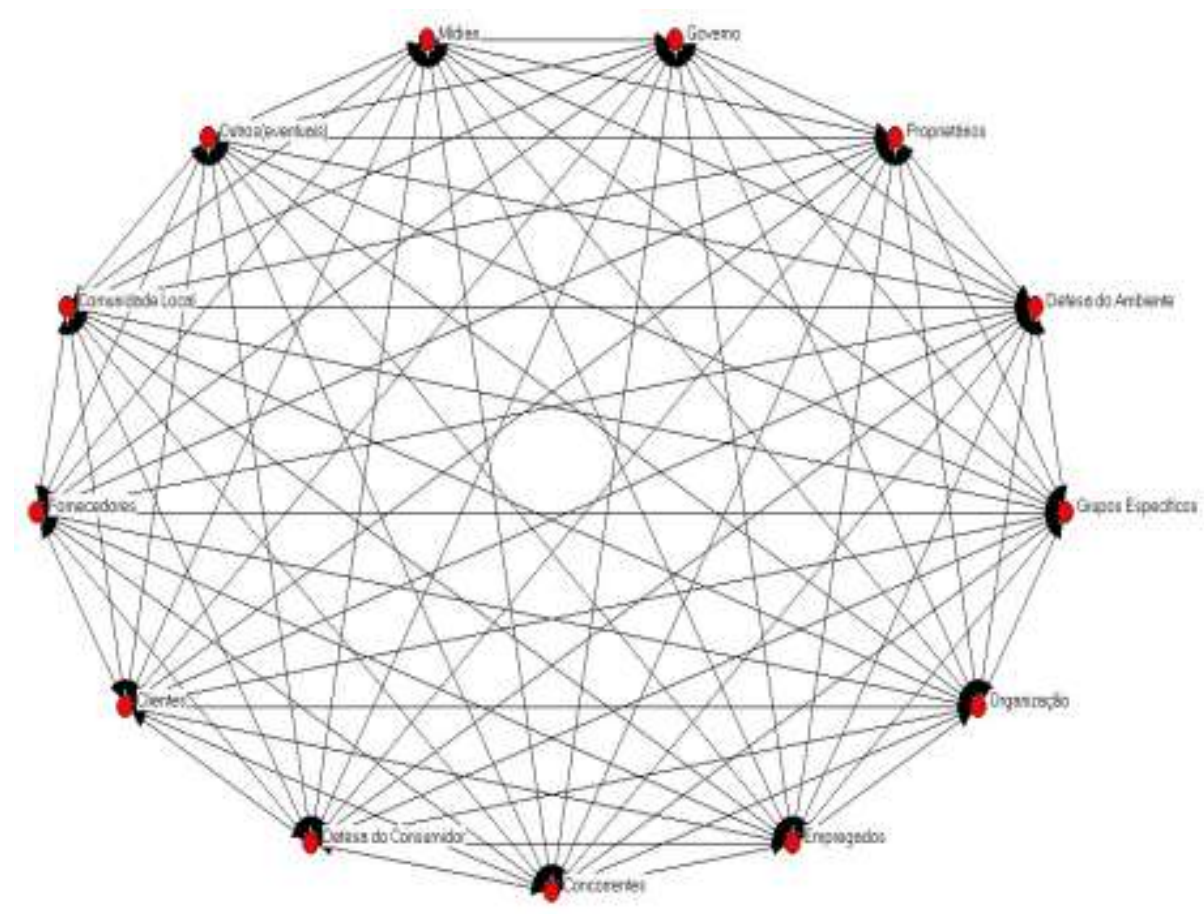

Fonte: Elaborado pelo autores com base na proposta de Rowley (1997)

Pode-se observar na Figura acima que os stakeholders mantêm algum tipo de relacionamento com os outros stakeholders da mesma rede de relacionamento. Pode-se deduzir, então, que um stakeholder dessa rede pode ter com outro stakeholder em outra rede, ampliando assim o nível de relacionamento e quantidade de envolvidos nas redes de relacionamentos, sendo as empresas do mesmo segmento ou não.

Enfim, o uso do UCINET para o propósito desta pesquisa está na intenção de apenas demonstrar graficamente como a rede de relacionamento da organização está caracterizada, se é perceptível a densidade da rede e se existe algum stakeholder exercendo a centralidade.

\section{RESULTADOS DA PESQUISA}

Os resultados da pesquisa indicam que cada uma das atividades de interação e relacionamento da empresa com seus stakeholders apresentam particularidades e características específicas, que devem ser cuidadosamente estudadas, tanto em relação à performance esperada (restrita à sua atividade), como em relação a seus impactos diretos e indiretos na estratégia da empresa.

Desse modo, afirmação de que a atenção nos stakeholders constitui elemento importante na definição das estratégias relacionadas ao mercado de bens simbólicos da educação, visto que, é preciso considerar os atributos de poder, legitimidade urgência no tratamento dispensado aos stakeholders da organização em decorrência do potencial que

Perspectivas em Gestão \& Conhecimento, João Pessoa, v. 8, n. 1, p. 86-116, jan./abr. 2018. 
dispõem para influenciar o comportamento, cultura, competitividade e até mesmo a lucratividade da empresa.

A identificação (Quadro 4) e maximização de eficiência do Mapa de Stakeholders da organização escolar, entendendo seus interesses e práticas, como parte da estratégia de geração de valores a partir das redes de relacionamentos, podem ser entendidas como a almejada capacidade de aglutinar, influenciar e se relacionar com os demais players de ambiente, objetivando uma maior vantagem competitiva tanto em relação a seus concorrentes.

Quadro 4 - stakeholders identificados

\begin{tabular}{|l|}
\hline Stakeholder \\
\hline Comunidade \\
\hline Coordenador Pedagógico \\
\hline Diretor Pedagógico \\
\hline Fornecedor Material Didático \\
\hline Funcionário Administrativo \\
\hline Governo em Geral \\
\hline Mantenedor \\
\hline Mídias em Geral \\
\hline Pais de Alunos \\
\hline Professores (Ens. Fund. 1 e 2, M édio) \\
\hline Supervisor Ensino \\
\hline Transportador Escolar \\
\hline
\end{tabular}

Fonte: Dados da pesquisa (2016)

Curiosamente, alguns stakeholders não foram citados pelos respondentes, como sindicato e concorrentes, embora esses também estejam, de alguma forma, relacionados com o ambiente da organização.

Para que todas as ações e atividades funcionem perfeitamente é necessário que alguns controles existam, o mais comum é o contrato entre partes, embora não seja comum entre todos os stakeholders.

No quadro 5 está descrito o que cada stakeholder utiliza como controle formal ou informal, para que suas ações ou atividades sejam exercidas na rede de relacionamento da Instituição de Ensino. Esse quadro foi desenvolvido a partir da observação não participante e com base nas entrevistas com os stakeholders.

Quadro 5 - Controles formais e informais entre o colégio e os stakeholders

\begin{tabular}{|l|l|}
\hline Relacionamento & Documento \\
\hline Colégio $=>$ Governo & Autorização \\
\hline Colégio $=>$ Fornecedor Material Didático & Contrato Formal \\
\hline Colégio $=>$ Professores & Contrato Formal \\
\hline Colégio $=>$ Pais de Alunos e Alunos & Contrato Formal \\
\hline Colégio $=>$ Transportador Escolar & Acordo Informal \\
\hline Colégio $=>$ Funcionários Adm. & Contrato Formal \\
\hline Colégio $=>$ Diretor Pedagógico & Contrato Formal \\
\hline Colégio $=>$ Coordenador Pedagógico & Contrato Formal \\
\hline Colégio $=>$ Comunidade & Nenhum Controle \\
\hline Colégio $=>$ Mídias em Geral & Contrato Formal na contratação de serviços \\
\hline Colégio $=>$ Supervisor de Ensino & $\begin{array}{l}\text { O Colégio recebe supervisão e a visita é registrada } \\
\text { num livro denominado Termo de Visita e }\end{array}$ \\
\hline
\end{tabular}

Perspectivas em Gestão \& Conhecimento, João Pessoa, v. 8, n. 1, p. 86-116, jan./abr. 2018. 
Fonte: Dados da pesquisa (2016)

Acompanhamento.

Os contratos formalizados entre as partes determinam as obrigações e deveres de cada parte envolvida e, caso uma das partes não cumpra o combinado, pode sofrer as sanções previstas nas leis. No entanto, os integrantes da rede de relacionamento da instituição de Ensino se esforçam no sentido de manter um ambiente de harmonia e cooperação, e quando acontece alguma divergência rapidamente é resolvida por meio de reuniões entre as partes envolvidas.

Após a identificação de quem são os stakeholders envolvidos no ambiente da organização (campo de pesquisa), foi elaborada uma classificação com base no Modelo de Saliência de Mitchell, Agle e Wood (1997) e na proposta de Phillips (1997) descritos no referencial teórico deste estudo.

Conforme descrito na metodologia, essa classificação foi elaborada mediante entrevistas realizadas com todos os participantes, no entanto, uma atenção maior foi dada para as indicações realizadas pelo mantenedor do colégio (organização campo de pesquisa).

A técnica de observação não participante ajudou muito nesse momento, no sentido de entender como cada stakeholder exerce sua participação, contribuição ou influência na rede de relacionamento.

O resultado da classificação de cada stakeholder seguindo o Modelo de Saliência de Mitchell, Agle e Wood (1997) e a proposta de Phillips (1997) está descrito no Quadro 6:

Quadro 6 - Resultado da classificação dos stakeholders

\begin{tabular}{|c|c|c|c|c|c|c|}
\hline \multirow{3}{*}{ Stakeholder } & \multicolumn{5}{|c|}{ Salience Model } & \multirow{3}{*}{$\begin{array}{l}\text { PHILLIPS } \\
\text { Legitimidade }\end{array}$} \\
\hline & \multicolumn{3}{|c|}{ Atributos } & \multirow{2}{*}{ Classificação } & \multirow{2}{*}{ Saliência } & \\
\hline & Poder & Legitimidade & Urgência & & & \\
\hline Aluno & & $x$ & & Discricionário & Baixa & Derivativa \\
\hline Comunidade & $x$ & $x$ & & Dominante & Moderada & Normativa \\
\hline $\begin{array}{l}\text { Coordenador } \\
\text { Pedagógico }\end{array}$ & $x$ & $x$ & & Dominante & Moderada & Normativa \\
\hline $\begin{array}{l}\text { Diretor } \\
\text { Pedagógico }\end{array}$ & $x$ & $x$ & & Dominante & Moderada & Normativa \\
\hline $\begin{array}{l}\text { Fornecedor } \\
\text { Material } \\
\text { Didático }\end{array}$ & $x$ & $x$ & & Dominante & Moderada & Normativa \\
\hline $\begin{array}{l}\text { Funcionários } \\
\text { ADM. }\end{array}$ & & $x$ & & Discricionário & Baixa & Normativa \\
\hline Governo & $x$ & $x$ & $x$ & Definitivo & Alta & Derivativa \\
\hline Mantenedor & $x$ & $x$ & $x$ & Definitivo & Alta & Normativa \\
\hline $\begin{array}{l}\text { Mídias em } \\
\text { Geral }\end{array}$ & $x$ & $x$ & & Dominante & Moderada & Derivativa \\
\hline Pais de Alunos & $x$ & $x$ & $x$ & Definitivo & Alta & Derivativa \\
\hline Professores & $x$ & $x$ & $x$ & Definitivo & Alta & Normativa \\
\hline $\begin{array}{l}\text { Supervisor de } \\
\text { Ensino }\end{array}$ & $x$ & $x$ & $x$ & Definitivo & Alta & Derivativa \\
\hline $\begin{array}{l}\text { Transportador } \\
\text { Escolar }\end{array}$ & & $x$ & & Discricionário & Baixa & Derivativa \\
\hline
\end{tabular}

Fonte: Dados da pesquisa (2016) 
Com base no resultado da Etapa 1, identificação dos stakeholders, foi elaborado um mapa dos stakeholders que poderiam participar das entrevistas, conforme descrito na Etapa 2 e 3 da coleta de dados.

O convite foi realizado (pessoalmente, por telefone ou e-mail) para cada potencial entrevistado, alguns não quiseram participar, entre eles foram quatro professores, três transportadores escolares, três representantes da comunidade e um fornecedor de material didático, este último inclusive não reportou o e-mail convite.

Não foi possível realizar entrevistas com representantes dos alunos, do Governo e das mídias em geral, pois em relação aos alunos optou-se por entrevistar seus pais ou responsáveis, visto que eles ainda são considerados menores de idade, ou seja, com idade inferior a 18 anos.

Representantes do Governo não puderam ser entrevistados em razão da dificuldade de se localizar uma pessoa responsável e com autorização, para participar das entrevistas. Da mesma forma, foram os representantes das mídias, pois abordou-se para efeitos dessa pesquisa, a mídia como um todo (jornais, revistas, televisão, rádio, internet, redes sociais eletrônicas etc.).

Dessa forma, o total de entrevistados que se disponibilizaram a fornecer informações foi 53, descritos no Quadro 7, por ordem alfabética.

Quadro 7 - Relação de stakeholders entrevistados (por ordem alfabética)

\begin{tabular}{|l|l|l|}
\hline Stakeholder & Código Identificação & Quantidade \\
\hline Alunos & AL & 0 \\
\hline Comunidade & CO & 02 \\
\hline Coordenador Pedagógico & CP & 01 \\
\hline Diretor Pedagógico & DP & 01 \\
\hline Fornecedor Material Didático & MD & 01 \\
\hline Funcionário Administrativo & FA & 12 \\
\hline Governo em Geral & GO & 0 \\
\hline Mantenedor & MA & 01 \\
\hline Mídias em Geral & MI & 0 \\
\hline Pais de Alunos & PA & 12 \\
\hline Professores (Ens. Fund. 1 e 2, Médio) & PR & 21 \\
\hline Supervisor Ensino & SE & 01 \\
\hline Transportador Escolar & TE & 01 \\
\hline Total & & $\mathbf{5 3}$ \\
\hline
\end{tabular}

Fonte: Dados da pesquisa (2016)

Para a Etapa 2 do procedimento de coleta de dados, foi utilizado o "Formulário de Poder e Identificação de Influência" que consistia em coletar informações dos entrevistados referentes à pergunta: quais são os cinco stakeholders que, em sua opinião, possuem maior poder de contribuir ou influenciar a organização (campo de pesquisa), tanto positiva quanto negativamente? Quadro 8:

Após agrupadas as respostas (total de cada indicação), os resultados estão descritos no 
Quadro 8 - Relação dos stakeholders que podem influenciar a organização. Por ordem de importância

\begin{tabular}{|l|l|l|l|l|}
\hline $\mathbf{1 0}$ & $\mathbf{2 0}$ & $\mathbf{3 0}$ & $\mathbf{4 0}$ & $\mathbf{5 0}$ \\
\hline 12 Professores & 13 Professores & 14 Professores & 8Func. Adm. & 12 Alunos \\
\hline 9 Pais de Alunos & 9 Diretor Ped. & 9 Coord. Ped. & 7 Diretor Ped. & 9Func. Adm. \\
\hline 8 Mantenedor & 8 Coord. Ped. & 8 Diretor Ped. & 7 Mat. Didático & 7 Pais de Alunos \\
\hline 6 Alunos & 7 Pais de Alunos & 5 Alunos & 7 Pais de Alunos & 5 Governo \\
\hline 6 Diretor Ped. & 3 Mantenedor & 4 Comunidade & 5 Professores & 5 Mat. Didático \\
\hline 3 Mat. Didático & 3Func. Adm. & 3Func. Adm. & 5 Coord. Ped. & 4 Coord. Ped. \\
\hline 3 Governo & 3 Alunos & 2 Transp. Escolar & 5 Alunos & 3 Comunidade \\
\hline 2 Coord. Ped. & 2 Sup. Ensino & 2 Pais de Alunos & 2 Sup. Ensino & 2 Professores \\
\hline 1 Sup. Ensino & 2 Mat. Didático & 2 Mantenedor & 2 Mantenedor & 2 Mantenedor \\
\hline 1 Mídia & 1 Transp. Escolar & 2 Governo & 2 Governo & 2 Mídia \\
\hline 1Func. Adm. & 1 Mídia & 1 Sup. Ensino & 1 Mídia & 1 Diretor Ped. \\
\hline 1 Comunidade & 1 Comunidade & 1 Mat. Didático & 1 Transp. Escolar & 1 Transp. Escolar \\
\hline
\end{tabular}

Fonte: Dados da pesquisa (2016)

O quadro 8 demonstra que o stakeholder percebido por todos que tende a influenciar a rede de relacionamento por meio de suas ações ou atividades é o professor. Esse stakeholder foi o mais indicado para os níveis de importância, 1ㅇ, 2으 e 3ㅇ․

Se forem observados os três primeiros indicados para o primeiro nível de importância, pode-se perceber que os stakeholders com maiores poderes de influenciar a rede de relacionamento são professores, pais de alunos e mantenedor. Essa sequência, em primeiro instante, pode parecer lógica, pois esses três indicados são considerados Stakeholders Definitivos, segundo a classificação pelo Modelo de Saliência de Mitchell, Agle e Wood (1997), descrita no Quadro 9.

Ao prosseguir para a segunda etapa, cada entrevistado indicou quais são os stakeholders que mais contribuem ou influenciam a organização (campo de pesquisa), também deveria indicar quais eram as influências ou contribuições que cada stakeholder exercia.

Quadro 9 - Síntese das contribuições e influências oriundas dos stakeholders da organização (campo de pesquisa)

\begin{tabular}{|c|c|}
\hline Stakeholders & Contribuições e Influências \\
\hline Alunos & $\begin{array}{l}\text { Vontade de aprender e dedicação; compromisso com os } \\
\text { objetivos pedagógicos; reconhecimento da Instituição; } \\
\text { bom relacionamento. }\end{array}$ \\
\hline Coordenador Pedagógico & $\begin{array}{l}\text { Gestão e trabalho em equipe; orientador, mediador e } \\
\text { facilitador; direcionador. }\end{array}$ \\
\hline Diretor Pedagógico & $\begin{array}{l}\text { Condução da equipe com foco nos objetivos; } \\
\text { direcionamento e trabalho em equipe; comunicação. }\end{array}$ \\
\hline Fornecedor Material Didático & $\begin{array}{l}\text { Comunicação e relacionamento; atualização e } \\
\text { desenvolvimento do material didático; orientação e } \\
\text { capacitação dos docentes; reconhecimento da instituição. }\end{array}$ \\
\hline Funcionário Administrativo & $\begin{array}{l}\text { Comunicação e prestatividade no atendimento; trabalho } \\
\text { em equipe; organização e segurança na informação; bom } \\
\text { relacionamento com todos. }\end{array}$ \\
\hline Governo em Geral & $\begin{array}{l}\text { Leis e normas; poder coercitivo através das leis; parcerias } \\
\text { em ações sociais. }\end{array}$ \\
\hline Mantenedor & $\begin{array}{l}\text { Gestão escolar; comunicação e prestatividade; honrar } \\
\text { compromissos. }\end{array}$ \\
\hline Mídias em geral & $\begin{array}{l}\text { Comunicação e divulgação de conhecimento, notícias e } \\
\text { eventos. }\end{array}$ \\
\hline
\end{tabular}

Perspectivas em Gestão \& Conhecimento, João Pessoa, v. 8, n. 1, p. 86-116, jan./abr. 2018. 


\begin{tabular}{|l|l|}
\hline Pais de Alunos & $\begin{array}{l}\text { Reconhecimento da instituição (reputação); } \\
\text { acompanhamento pedagógico e participação na educação } \\
\text { dos filhos; comunicação e divulgação do colégio; } \\
\text { responsabilidade pelo pagamento das mensalidades. }\end{array}$ \\
\hline $\begin{array}{l}\text { Professores (Ens. Fund. 1 e 2, } \\
\text { Médio) }\end{array}$ & $\begin{array}{l}\text { Comunicação; compromisso com o desenvolvimento do } \\
\text { conhecimento; trabalho em equipe; desenvolvimento das } \\
\text { práticas pedagógicas; relacionamento com base no } \\
\text { direcionamento, confiança e segurança. }\end{array}$ \\
\hline Comunidade & $\begin{array}{l}\text { Comunicação e divulgação dos eventos e ações sociais } \\
\text { realizadas no colégio; envolvimento e participação nas } \\
\text { atividades do colégio. }\end{array}$ \\
\hline Supervisor de Ensino & $\begin{array}{l}\text { Comunicação e relacionamento baseado na confiança e } \\
\text { direcionamento; acompanhar a execução das leis e } \\
\text { normas vigentes; participação na solução de conflitos. }\end{array}$ \\
\hline Transportador Escolar & $\begin{array}{l}\text { Confiança, segurança e pontualidade; bom } \\
\text { relacionamento com pais e colégio. }\end{array}$ \\
\hline
\end{tabular}

Fonte: Elaborado pelos autores com base em Bardin (1977)

Os resultados da pesquisa corroboram a necessidade de se atualizar criticamente os pressupostos da teoria dos stakeholders no sentido de sua constante atualização. Na presente pesquisa, as variáveis do estudo foram definidas com base na necessidade teórica, pois o modelo utilizado para a classificação dos stakeholders necessitava da análise dos atributos de poder, legitimidade e urgência. Outra variável observada foi a que a representava o valor percebido por cada stakeholder oriundo das suas atividades e ações na rede de relacionamento. Para os estudos de rede sociais, com base na proposta de Rowley (1997), foi necessário apenas identificar a densidade e a centralidade da rede de relacionamento da instituição estudada.

Para Rowley (1997) corroborando com Nohria e Eccles (1992), uma organização depende dos múltiplos níveis de relacionamento envolvendo diversos stakeholders, cada um contribuindo com recursos e serviços no intuito de obter melhores resultados.

Algumas características cruciais para o entendimento do nível de relacionamento foram observadas a partir da coleta de dados. Alguns entrevistados frisaram a questão do compromisso, da cooperação entre os envolvidos e da confiança nas atividades realizadas, indo ao encontro ao citado por alguns atores que reforçam que para um relacionamento duradouro, os envolvidos não podem apenas observar os interesses econômicos, mas que o comprometimento, a cooperação e a confiança devem existir nos níveis de relacionamento na rede (TICHY; TUSHMAN; FOMBRUN, 1979; FREEMAN, 1984; ROWELY, 1997; GRANOVETTER, 2007).

O Modelo de Saliência proposto por Mitchell, Agle e Wood (1997) contribuiu para este estudo no que se refere ao entendimento, por parte da instituição de ensino (campo de pesquisa), de quem são os considerados Stakeholders Definitivos que merecem uma atenção especial por possuírem os atributos de poder, legitimidade e urgência.

Nesse sentido, foi observado que os stakeholders governo, pais de alunos, professores e supervisor de ensino foram classificados como Stakeholders Definitivos, com base no Modelo de Saliência de Mitchell, Agle e Wood (1997).

As ações desses stakeholders, considerados definitivos, devem ser acompanhadas de perto, pois podem trazer resultados significativos (positivos ou negativos) para a instituição. Segundo Mitchell, Agle e Wood (1997, p. 865), os stakeholders que possuem os três atributos (poder, legitimidade e urgência) devem receber uma atenção especial da organização no que se refere ao atendimento e à prioridade dos seus interesses. 
A instituição de ensino, com base na proposta de Freeman (1984) para as Estratégias Genéricas em relação aos stakeholders, descrita na Figura 3, deve observar o poder relativo de cooperação e a ameaça competitiva relativa para se posicionar em relação às ações de cada stakeholder. A organização deve se posicionar de maneira a MUDAR AS REGRAS sempre que necessário em relação aos stakeholders pais de alunos e professores, pois as ações desses stakeholders podem gerar uma alta ameaça competitiva, mas possuem, também, um alto poder de cooperação em relação às atividades da escola.

Para o stakeholder Governo, a instituição deve se posicionar de forma a MANTER a maneira como atua, pois as ações do Governo oferecem uma ameaça competitiva relativamente baixa e o poder de cooperação também é baixo.

Já para o stakeholder supervisor de ensino, a instituição deve se posicionar de forma a EXPLORAR as contribuições desse profissional, pois ele possui um baixo poder de ameaça competitiva, mas pode ter um alto potencial de cooperação nas ações da rede de relacionamento.

Para a análise do posicionamento da instituição de ensino na rede de relacionamento com base na proposta de Rowley (1997), observou-se primeiramente que a densidade da rede (refere-se à conectividade da rede) é de $87,82 \%$ se observados apenas os tipos de stakeholders na rede e sua relação. Se observadas todas as indicações de relações entre os entrevistados, nota-se que a densidade diminuiu um pouco, ficando em $78,81 \%$.

A centralidade da rede (posição de um stakeholder na rede em relação aos outros é exercida pelos stakeholders MA - mantenedor; CP - coordenador pedagógico; DP - diretor pedagógico e os funcionários administrativos FA03 e FA05).

Observa-se, então, que a centralidade da rede é exercida por membros dessa instituição, com isso, de acordo com a proposta de Rowley (1997), a organização (campo de pesquisa) deve manter uma estratégia CONCILIADORA, ou seja, como a organização tem alta centralidade da rede e a rede tem uma densidade alta, essa estratégia (CONCILIADORA), segundo Rowley (1997), é a mais indicada para a continuidade das atividades, pois qualquer influência na rede de relacionamento pode ser perigosa.

Como resultado deste estudo, pode-se observar que a proposta de Freeman (1984) se adapta perfeitamente, quando indica que a organização está no centro das atenções. No entanto, esse resultado pode ter sido uma coincidência e outros estudos com organizações do mesmo segmento poderão ser realizados para comprovar se a proposta de Freeman (1984) está perto da realidade, ou se a proposta de Rowley (1997) tende a demonstrar uma mudança de posicionamento da organização em relação a sua rede de relacionamento.

Como proposta para observação dos valores percebidos pelos stakeholders na rede de relacionamento, o que se pode observar foi que, além do pagamento pelos serviços prestados oriundos das atividades de cada stakeholder, há a percepção de valores intangíveis como reconhecimento (qualidade e reputação), status, confiança, satisfação, desenvolvimento e transmissão do conhecimento.

Conforme observado, os stakeholders considerados definitivos, governo, pais de alunos e professores, procuram obter uma maior ou melhor vantagem em relação a suas ações na rede de relacionamento. O governo, pela própria questão das leis e recolhimento dos impostos; os pais de alunos sempre negociando junto ao colégio um desconto nas mensalidades de seus filhos, uma estrutura física melhor, profissionais mais qualificados etc.; e os professores buscando melhores salários, oportunidades de crescimento na área e melhores treinamentos.

Para o fornecedor de material didático - MD, as relações comerciais com a instituição de ensino são importantes porque a reputação e o reconhecimento no mercado são fatores primordiais para que esse material possa se propagar e se fortalecer no mercado. Para o transportador escolar - TE, uma instituição de ensino com uma boa reputação pode atrair mais

Perspectivas em Gestão \& Conhecimento, João Pessoa, v. 8, n. 1, p. 86-116, jan./abr. 2018. 
alunos e, com isso, maiores oportunidades de ofertar os serviços de transporte, e para os pais de alunos - PA, a instituição sempre oferta bons descontos para o próximo período letivo, com isso conseguem atrelar um ensino de qualidade a um preço satisfatório dentro do orçamento familiar.

Com base nos resultados das entrevistas, pode-se observar que existe a preocupação por partes dos entrevistados em relação à equidade e ao compromisso moral, principalmente por parte da instituição de ensino. Os entrevistados relataram que percebem a questão da equidade no tratamento e nas negociações com o colégio, que demonstra real interesse em honrar com todos os seus compromissos.

A questão da equidade e do compromisso moral, inclusive, foi bem destacada pelo fornecedor de material didático e ainda pelos funcionários administrativos. Para os professores, esse é um fator muito importante, e para os pais de alunos é visível o esforço que o colégio faz para ofertar uma política de descontos que possa contemplar a maior parte dos alunos.

Para os stakeholders governo e supervisor de ensino, o que se pode observar é que existe um compromisso por parte da instituição de ensino em relação a honrar com suas obrigações, sejam elas tributárias ou de ordem pedagógica.

Para a continuidade das relações, os stakeholders necessitam das ações ou atividades dos outros stakeholders envolvidos na rede de relacionamento. Por haver essas diversas atividades, sinais de confiança, cooperação e comprometimento devem ser observados para que o objetivo de cada relação seja alcançado (TICHY; TUSHMAN; FOMBRUN, 1979; FREEMAN, 1984; ROWELY, 1997; GRANOVETTER, 2007).

Nesse ponto da análise é preciso destacar as peculiaridades de cada stakeholder, visto que, na observação não participante, quanto pela apuração dos resultados das entrevistas, foram percebidos sinais de confiança e cooperação, exemplo disso são as atividades pedagógicas entre os professores, que na maioria das vezes são realizadas em conjunto. Trabalho em equipe foi mencionado diversas vezes nas entrevistas.

A preocupação por parte dos pais de alunos em relação ao aprendizado dos seus filhos faz com que haja um compromisso em relação ao acompanhamento da evolução da aprendizagem desses alunos. Alguns pais participam ativamente das reuniões programadas no colégio e buscam, por meio de parcerias com os professores, sanar algumas dificuldades que seus filhos (os alunos) têm.

O fornecedor de material didático, como proposta de fortalecimento da parceria, se comprometeu a trocar a capa das apostilas que fornece para a instituição de ensino, aceitando assim, colocar uma capa que compartilha informações tanto do sistema quanto da instituição de ensino. Nesse sentido, a cooperação e o compromisso ficam evidentes no que se refere às ações para o fortalecimento das duas organizações envolvidas.

Entre os transportadores escolares - TE também foram percebidos os sinais de confiança, comprometimento e cooperação. Um exemplo disso está no fato de que foi observado que quando um transportador escolar tem seu veículo inviabilizado para o transporte por qualquer motivo que seja, outro transportador escolar - TE se oferece para conduzir seus alunos. Percebe-se que há uma preocupação com o resultado final, ou seja, o aluno precisa estar no colégio no horário correto e ser entregue na sua residência dentro do prazo estipulado.

Em relação às ações do supervisor de ensino, como já observado, são apenas de controle e direcionamento, no entanto, sempre que necessário esse profissional entra em ação no sentido de gerenciar conflitos entre pais de alunos, comunidade e colégio, buscando a todo custo uma forma de resolver as dificuldades apresentadas.

Os resultados das entrevistas bem como a observação não participante contribuíram muito no sentido de observar como as ações e atividades na rede de relacionamento 
acontecem, como essas atividades são compartilhadas e como os sinais de compromisso e cooperação vão surgindo, pois o que se pode perceber é que, para os envolvidos, o importante é que os objetivos da instituição de ensino sejam alcançados como forma dos objetivos particulares serem também contemplados.

Assim, foi possível detectar a existência de uma rede de relacionamento estabelecida voltada para os princípios de cooperação, confiança e compromisso e que os stakeholders nessa rede estão envolvidos para o alcance do objetivo final da Instituição de Ensino.

\section{CONSIDERAÇÕES FINAIS}

O presente estudo alicerçado em três eixos teóricos: características do mercado de bens simbólicos, teoria dos stakeholders e abordagens estratégicas nas redes de relacionamentos com a intenção de contribuir para o entendimento da atuação dos stakeholders na rede de relacionamento de uma organização do mercado de bens simbólicos da educação.

A vertente Salience Model da teoria dos stakeholders propiciou subsídios importantes para se entender quem são e como atuam os interessados nas ações e atividades da instituição de ensino. Para se analisar a dinâmica presente na rede de relacionamento foi utilizada a Teoria da abordagem social que contribuiu no sentido de observar como as relações acontecem no sentido de fortalecimento das atividades conjuntas.

A pesquisa realizada em três etapas (pesquisa bibliográfica, entrevistas e análise de conteúdo), permitiu constatar que há uma rede de relacionamento bem estabelecida, com base nos princípios de cooperação, confiança e compromisso e que os stakeholders envolvidos nessa rede procuram cooperar para o alcance do objetivo final que é a formação do aluno por meio da prestação de serviços educacionais da instituição de ensino.

$\mathrm{Na}$ presente pesquisa, cada stakeholder envolvido demonstrou estar satisfeito com a forma como atua, como percebe os valores criados e distribuídos pela Instituição de Ensino, e salientou que não tem interesse ou intenção em sair dessa rede de relacionamento.

O emprego do software UCINET permitiu visualizar graficamente como uma rede é formada em seu todo, quais são os nós e laços, identificar grau de centralidade e densidade da rede entre outros fatores para se entender criticamente a atuação dos stakeholders numa rede de relacionamento. Nessa perspectiva, o modelo de Freeman (1984) e Rowley (1997) para a teoria dos stakeholders puderam ser incorporados no modelo das Redes Sociais para se compreender a atuação dos stakeholders no mercado de bens simbólicos da educação. Também, podem-se destacar as reflexões em relação à Teoria das Redes Sociais, cujas premissas podem proporcionar a compreensão dos relacionamentos, visto que essas se voltam para as ações ou atividades primordialmente direcionadas para o bem coletivo, cujo resultado final tende a ter suas relações fortalecidas pela política do ganha - ganha, observando os princípios de equidade e compromisso moral.

Evidentemente apresente proposta de pesquisa tem em suas limitações. As pesquisas acadêmicas ou científicas, em casos específicos, podem apresentar certo grau de dificuldade quando o pesquisador inicia a fase de coleta de dados, pois passa a depender dos agendamentos, das disponibilidades dos entrevistados entre outros contratempos.

O tamanho da amostra, também, para algumas pesquisas, pode ser um fator limitador, pois os resultados não podem ser considerados representativos e, com isso, a replicação pode ser prejudicada principalmente na análise. $O$ fato de o objeto de estudo ser uma rede de relacionamento de uma organização educacional, com isso a amostra para compor o número de stakeholders pôde ser considerada pequena, neste caso, foram entrevistados 53 stakeholders.

Perspectivas em Gestão \& Conhecimento, João Pessoa, v. 8, n. 1, p. 86-116, jan./abr. 2018. 
Outro fator que pode ser considerado como limitação está no fato da dificuldade de acesso a documentos confidenciais ou reservados que poderiam reforçar algum ponto crucial da pesquisa, como exemplo o relatório de desempenho econômico, os custos operacionais e de transação entre outros.

Como proposta para futuras pesquisas sugere-se estudos de caso múltiplo envolvendo três ou mais redes de relacionamento do mesmo segmento e que os resultados possam ser comparados por meio de pesquisa quantitativa para que, estatisticamente, possa ser verificado como cada rede alcança melhores resultados tanto em desempenho quanto em distribuição de valores.

\section{REFERÊNCIAS}

AZEVEDO, D. B. Diálogos entre Stakeholders em redes de organizações de agronegócios na busca da mitigação dos efeitos da mudança climática: o caso do Instituto do Agronegócio responsável - ARES. 2010. 280f. Tese (Doutorado em Agronegócios) - Universidade Federal do Rio Grande do Sul, Porto Alegre, 2010.

BARAKATI, S. R; FREITAS, L. P; BOAVENTURA, J. M. B; MCLENNAN, M. L. F. Legitimidade: análise da evolução do conceito na teoria do stakeholders. Revista de Ciências da Administração. Florianopolis, v. 18, n. 44, p. 66-80, abr. 2016.

BARDIN, L. Análise de conteúdo. Lisboa, Portugal: Edições 70, 1977.

BAZANINI, R. $O$ ensino de filosofia como um processo existencial humano. O Método Bazanini no ensino de filosofia. Filosofia aplicada à administração. São Paulo: Plêiade, 2005.

BAZANINI, R; FERREIRA, A.A; MACHADO, C. GIRADELLI, G.Estratégias no mercado de bens simbólicos do turismo: o segmento single. PODIUM Sport, Leisure and Tourism Review, v. 4, n. 1, p. 62, 2015.

BAZANINI, R; MIKLOS, J; BAZANINI, H.L; GIRADELLI G.. O mercado de bens simbólicos: a viabilidade política e midiática do Templo de Salomão junto aos stakeholders. Comunicação \& Informação, v. 19, n. 2, 2016.

BERTON, R; Bazanini, R; DONAIRE, D. Mercado de bens simbólicos do futebol: a estratégia empreendedora da gestão Andrés Sanchez no Sport Club Corinthians Paulista. PODIUM Sport, Leisure and Tourism Review v. 2, n. 1, p. 25, Jan./Jun., 2013.

BOURDIEU, P. A Economia das Trocas Simbólicas. São Paulo, Perspectiva, 2005.

. O Poder Simbólico. Rio de Janeiro: Bertrand Brasil, 2007.

BRANDENBURGER, A. M.; NALEBUFF, B. J. Co-opetição. Rio de Janeiro: Rocco, 1996.

BOAVENTURA, J. M. G, BANDEIRA-DE-MELLO, R., MONZONI, M. P., SIMONETTI, R., SARTURI, G. Limites da Teoria dos Stakeholders: a Questão da Dominância. In: Encontro da ANPAD, XXXVII, Rio de Janeiro. Anais... Rio de Janeiro, EnANPAD, 2013. 
BOURDIEU, P., PASSERON, J. C. Os herdeiros: os estudantes e a cultura. Florianópolis: EDUFSC, 2013

CASTELLS, M. A sociedade em rede. São Paulo: Editora Paz e Terra, 1999.

. Materials for an exploratory theory of the network society. British Journal of Sociology, v.51, n.1, Jan/Fev, p.5-24, 2000

CLARKSON, M. B. E. A Stakeholder Framework for Analyzing and Evaluating Corporate Social Performance. Academy of Management Review, Mississipi - USA, v.20, p. 92 -117, jan. 1995.

DIMAGGIO, P.; POWELL, W. The iron cage revisited - institutional isomorphism and a collective rationality in organizational fields. American Sociological Review, v.48, n.2, p. 147-160, 1983.

DONALDSON, T.; PRESTON, L. E. The Stakeholder Theory of the Corporation: Concepts, Evidence, and Implications. The Academy of Management Review. New York - USA, v. 20, n. 01, p. 65-91., jan.1995.

EISENHARDT, K. M. Building theories from case study research. The Academy of Management Review, New York - USA,v. 14, n. 4, p. 532-550, out.1989.

EVAN, W; FREEMAN, R,E. A stakeholder theory of the modern corporation: Kantian Capitalism. Ethical Theory and Business. 5a. ed. Englewood Ethics Prentice Hall, 1988.

FOUCAULT, M. Microfísica do Poder. Org. Roberto Machado, Rio de Janeiro: Edições Graal, 1982.

FREEMAN, R. E. A Stakeholder Approach. London: Pitman: 1984.

. Managing for Stakeholders. Darden School of Business, University of Virginia, Virginia, USA, jan. 2007.

FREEMAN, R. E.; REED, D. L. Stockholders and stakeholders: a new perspective on Corporate Governance. California Management Review, California, v. 25, n. 3, 1983.

FROOMAN, J. Stakeholder Influence Strategies. Academy of Management Review. New York, v. 24, n. 2, p.191-205, 1999.

GIL, A. C. Métodos e técnicas de pesquisa social. 6. ed. São Paulo: Atlas, 2008.

GODOY, A. S. Introdução à pesquisa qualitativa e suas possibilidades. In: Revista de Administração de Empresas. São Paulo: v.35, n.2, p. 57-63, abril 1995.

GONÇALVES, P. C., BOAVENTURA, J. M. G., COSTA, B. K., FISCHMANN, A. A. Stakeholders na atividade hospitalar: uma investigação setorial no Estado de São Paulo. Revista de Administração FACES Journal, v.7, n.2, p. 84-101, 2008.

GULATI, R.; NOHRIA, N.; ZAHEER, A. Strategic Networks. Strategic Management Journal, v. 21, n. 3, p. 203-215, 2000.

Perspectivas em Gestão \& Conhecimento, João Pessoa, v. 8, n. 1, p. 86-116, jan./abr. 2018. 
GRANOVETTER, M. Ação econômica e estrutura social: O problema da imersão. RAE - Revista de Administração de Empresas, v. 6, n. 1, p.1-41, 2007.

HINGLEY, M. K. Power to all our friends? Living with imbalance in supplier-retailer relationships. Industrial Marketing Management, v. 34, n. 8, p. 848-858, 2005.

JONES, T.M. Instrumental stakeholder theory: a synthesis of ethic and economics. The Academy of Management Review. New York, v. 20, n. 2, p. 404-437, 1995.

KRAUSZ, R. R. O poder nas organizações. São Paulo: Nobel, 1988.

MALHOTRA, N. Pesquisa de marketing. 3.ed. Porto Alegre: Bookman, 2001.

MARKOFF, J. Democracia: transformações passadas, desafios presentes e perspectivas futuras. Dossiê. p.18-50. Ano 15, n. 32, jan./abr.2013.

MARTINS, R. S. Estudo da formação do frete rodoviário e potencial de conflitos em negociações em cadeias do agronegócio brasileiro. Organizações Rurais e Agroindustriais, v. 10, p. 75-89, 2008.

MAYER, M. M. Futebol: o negócio por trás do jogo: Estudo de Caso do São Paulo Futebol Clube. Dissertação (Mestrado Executivo em Gestão Empresarial) - FGV. Escola Brasileira de Administração Pública e de Empresas, Rio de Janeiro, 2010.

MELO, P. T. N. B.; RÉGIS, H. P. Classificação dos laços entre gestores e Stakeholders na rede dos pontos de cultura no grande Recife. Organizações e Sociedade, Salvador, v. 20, n. 64, p. 75-96, mar. 2013.

MINAYO, M. C.S. Pesquisa social: teoria, método e criatividade. Rio de Janeiro: Vozes, 2001.

MINTZBERG, H.O Processo da Estratégia. São Paulo: Bookman, 2006.

MITCHELL, R. K., AGLE, B. R. e WOOD, D. J. Toward a Theory of Stakeholder Identification and Salience: Defining the Principle of Who and What Really Counts. The Academy of Management Review, New York, v. 22, n.4, p. 853-886, 1997.

MORAES, R. Análise de conteúdo. Revista Educação, Porto Alegre, v. 22, n. 37, p. 7-32, 1999.

MOREIRA, A. S. A religião sob o domínio da estética. Horizonte, Belo Horizonte, v. 13, n. 37, p. 379-405, 2015.

NISHIMURA, S. P. A precarização do trabalho docente como necessidade do capital: um estudo sobre o Reuni na UFRGS. 2012. 139 f. Dissertação (Mestrado em Educação) - Programa de Pós-Graduação em Educação, Universidade Federal do Rio Grande do Sul, Porto Alegre, 2012.

NOHRIA, N. Is a network perspective a useful way of studying organizations? In: NOHRIA, N.; ECLES, R. Networks and organizations: Structure, form, and action. Boston: Harvard Business School, 1992.

Perspectivas em Gestão \& Conhecimento, João Pessoa, v. 8, n. 1, p. 86-116, jan./abr. 2018. 
PFEFFER, J.; SALANCIK, G. The external control of organizations: a resource dependence perspective. New York:Harper \& Row, 1978.

PHILLIPS, R. A. Stakeholder theory and organizational ethics. San Francisco: Berret Koehler Publishers, 2003.

\section{$\overline{51-66,1997 .}$}

Stakeholder theory and a principle of fairness. Business Ethics Quarterly, v. 7, n. 1, p.

POST, J. E., PRESTON, L. E., Sauter-Sachs, S. Redefining the corporation: Stakeholder management and organizational wealth. Stanford University Press, 2002.

REED, I. A. Poder: dimensões relacional, discursiva e performática. Sociedade e Estado. Brasília, v. 29, n. 2, p. 473-510, 2014.

RICCOBONO, F.; BRUCCOLERI, M.; PERRONE, G. Business agreements objectives and decisions: a field research. Management Research Review, v. 36, n. 5, p. 495-527, 2013.

ROWLEY, T. J. Moving beyond Dyadic Ties: A Network Theory of Stakeholder Influences. The Academy of Management Review, New York, v.22, n. 4, p. 887-910, 1997.

SAVAGE, G. T.; NIX, T. W.; WHITEHEAD, C. J.; BLAIR, J. D. Strategies for assessing and managing organizational stakeholders. The Academy of Management Executive, New York, v.5, n.2, p. 61-75, 1991.

TICHY, N. M.; TUSHMAN, M. L.; FOMBRUN, C. Social network analysis for organizations. Academy of Management Review, v. 4, n. 4, p. 507-519, 1979.

THE CLARKSON CENTRE FOR BUSINESS ETHICS. The Clarkson Principles. Toronto: The Clarkson Centre for Business Ethics, 1999.

VERGARA, S. C. Projetos e relatórios de pesquisa em administração. 3. ed. Rio de Janeiro: Atlas, 2000.

WASSERMAN. S.; GALASKIEWICS J. Advances in social network analysis. Research in the social and behavioral sciences. Thousand Oaks. CA Sage. 1994.

YIN, R. K. Estudo de Caso: planejamento e métodos. 4. ed. Porto Alegre: Bookman, 2010.

ZACCARELLI, S. B. et al. Clusters e Redes de Negócios. São Paulo: Atlas, 2008.

ZAHEER, A.; GOZUBUYUK, R.; MILANOV, H. It's the connections: the networks perspective in interorganizational research. The Academy of Management Perspectives, v. 24, n. 1, fev. 2010. p. 62-77.

Artigo recebido em 02/07/2017 e aceito para publicação em 06/02/2018 